\title{
Musculoskeletal disorders and complaints in professional musicians: a systematic review of prevalence, risk factors, and clinical treatment effects
}

\author{
Gabriele Rotter $^{1,2,3}$ (D) $\cdot$ Katharina Noeres $^{1} \cdot$ Isabel Fernholz $^{2,3,4} \cdot$ Stefan N. Willich $^{1,3} \cdot$ Alexander Schmidt $^{2,3,5}$. \\ Anne Berghöfer ${ }^{1,3}$
}

Received: 6 December 2018 / Accepted: 19 July 2019 / Published online: 3 September 2019

(c) The Author(s) 2019

\begin{abstract}
Purpose Musicians' practice and performance routines reportedly lead to musculoskeletal complaints and disorders (MCD) that impact their wellbeing and performance abilities. This systematic review aims to assess the prevalence, risk factors, prevention and effectiveness of treatments for MCD in professional musicians and consider the methodological quality of the included studies.

Methods A systematic literature search was performed in December 2017 using electronic databases and supplemented by a hand search. Case-control studies, cohort studies, cross-sectional studies, interventional studies and case reports investigating the prevalence, risk factors, prevention or treatment effects of MCD in professional musicians or music students (age $\geq 16$ years) were included. Quality assessments of the included studies were performed using an adapted version of the "Study Quality Assessment Tools" from the National Heart, Lung, and Blood Institute.

Results One case-control study, 6 cohort studies, 62 cross-sectional studies, 12 interventional studies and 28 case reports were included and assessed for methodological quality. The study designs, terminology, and outcomes were heterogeneous, as the analyses mostly did not control for major confounders, and the definition of exposure was often vague. Therefore, evidence that being a professional musician is a risk factor for MCD as well as the causal relationship between these factors remains low despite the fact that a large number of studies have been performed.

Conclusions Studies with high internal and external validity regarding the prevalence, risk factors and effectiveness of the prevention or treatment of MCD in professional musicians are still missing. Further high-quality observational and interventional studies are required.
\end{abstract}

Keywords Musicians' medicine $\cdot$ Occupational medicine $\cdot$ Playing-related musculoskeletal disorders $\cdot$ Prevalence Incidence $\cdot$ Systematic review

Electronic supplementary material The online version of this article (https://doi.org/10.1007/s00420-019-01467-8) contains supplementary material, which is available to authorized users.

Gabriele Rotter

gabriele.rotter@charite.de

$1 \quad$ Institute for Social Medicine, Epidemiology and Health Economics, Charité - Universitätsmedizin Berlin, Luisenstrasse 57, 10117 Berlin, Germany

2 Kurt-Singer-Institute for Music Physiology and Musicians' Health, Hanns Eisler School of Music Berlin and University of the Arts Berlin, Charlottenstrasse 55, 10117 Berlin, Germany
3 Berlin Center for Musicians' Medicine, Charité - Universitätsmedizin Berlin, Luisenstrasse 13, 10117 Berlin, Germany

4 Department of Psychiatry and Psychotherapy, Charité - Universitätsmedizin Berlin, Charitéplatz 1, 10117 Berlin, Germany

5 Department of Audiology and Phoniatrics, Charité - Universitätsmedizin Berlin, Luisenstrasse 13, 10117 Berlin, Germany 


\section{Introduction}

To a great extent, professional musicians rely on their physical and mental health to guarantee their vocational and artistic positions, meet high audience demands or succeed in competitive settings. Even minor complaints may impair the precision of motion sequences and musical technique, thus creating a major threat to the artist's existence.

The discipline of musicians' medicine dates back to the 18th century (Ramazzini 1705). In the 1920s, Kurt Singer first systematically described symptoms of musicians' vocational diseases and their treatment (Singer and Lakond 1932; Harman 1993). Currently, musicians' medicine is dedicated to the prevention, diagnosis and therapy of health problems which may arise or have arisen as a result of making music or which have an effect on making music (Spahn et al. 2011).

In clinical practice, musculoskeletal and mental problems, especially performance anxiety, are very common amongst professional musicians (Fishbein et al. 1988). Up to now, several narrative and systematic reviews exist that provide data on a wide range of playing-related symptoms and diseases, with broadly varying prevalence rates (Harman 1982; Zaza 1998; Milan 1996; Zuskin et al. 2005). The varying prevalence rates may mainly be caused by the lack of a precise definition of playing-related symptoms and diseases as well as a lack of coordinated research.

Reviews of publications including patients with musculoskeletal complaints and disorders (MCD) used different definitions of musculoskeletal disorders or simply referenced "overuse syndrome" (Hoppmann and Patrone 1989; Bejjani et al. 1996). In 1998, Zaza (1998) introduced the term "playing-related musculoskeletal disorders" (PRMD), which aggregated the various musculoskeletal disorders while assuming a common etiological factor. The prevalence of PRMD in musicians was thus deemed to be comparable to vocation-related musculoskeletal disorders in other professions.

The most recent systematic review by Bragge et al. (2006) furthered the use of PRMD as an aggregate term for overuse syndrome, repetitive strain injuries or cumulative trauma disorders. The review reported a prevalence ranging between 26 and 93\%. Further systematic reviews added only limited information, as they did not use predefined review protocols or used a narrow search strategy (Wu 2007; Moraes and Antunes 2012). Furthermore, previous reviews did not focus on the methodological quality of the included studies.

Since various musculoskeletal disorders were inconsistently summarized under the term PRMD and the methodological quality of included publications was not assessed in previous reviews, we aimed to perform a comprehensive systematic review including published literature without language restrictions, based on an elaborated study protocol, to assess the prevalence, risk factors, prevention and effectiveness of MCD treatment in professional musicians, including the assessment of the methodological quality of the included studies.

\section{Methods}

The research methods and reporting of this study followed the Preferred Reporting Items for Systematic reviews and Meta-Analyses (PRISMA) guidelines (Liberati et al. 2009; Moher et al. 2009) and the recommendations of the Cochrane Collaboration (Green and Higgins 2011). Prior to conducting the review, a study protocol was prepared by all of the review authors, placing special emphasis on study selection, data extraction and quality assessment.

\section{Criteria for considering studies for the current review}

\section{Types of studies}

Observational studies (case-control studies, cohort studies, cross-sectional studies), intervention studies (controlled clinical trials and pre-post intervention studies without a control group), case reports and case series reporting clinical interventions published in peer-reviewed journals without language or publication date restrictions were included in this review. Studies published in non-peer-reviewed journals, theses, and gray literature were excluded.

\section{Types of participants}

Participants in the included studies were male or female professional musicians of all musical genres, including music teachers, instrument teachers and music students in higher education institutions (for example, universities, colleges, conservatories). Studies examining mixed professional populations (amateur, semi-professional/professional) or mixed artistic populations (musicians, actors, dancers) were included only if results were reported for the respective subgroups. When the professional status of the participants was not clearly defined in the publication, a consensus of the reviewing authors was obtained. For studies involving high school music students, participants had to be of at least 16 years of age (defined in this review as "adult") to be included. Publications on mixed populations (children, adolescents, adults) were included only if results were reported for the respective subgroups. The included studies investigated MCD that was potentially caused by or thought to be 
related to practicing or performing music. This also included dental and jaw diseases, myofascial pain syndromes, craniomandibular dysfunctions, shoulder belt compression syndromes (like thoracic outlet syndrome and congestion syndrome of the upper thoracic aperture) and percussion hemoglobinuria. Studies lacking relevant information on the different types of participants were excluded.

\section{Types of interventions}

Studies investigating the effectiveness or efficacy of any type of clinical intervention, including interventions using complementary and integrated medicine in the defined study population, were considered.

\section{Types of comparisons}

A control group comparison was not required to meet the eligibility criteria.

\section{Types of outcome measures}

Studies were considered if the primary outcomes included the prevalence, incidence or other information about the prevalence of MCD or risk factors for MCD or clinical treatment effects due to an intervention (preventive, therapeutic or rehabilitative). Studies providing only non-clinical treatment effects or validating methods of measurements were not included.

\section{Data sources and searches}

The electronic databases MEDLINE and EMBASE via OvidSP and via EbscoHost CINAHL, PsycArticles, PsycInfo and ERIC were searched between January 6th, 2015 and December 7th, 2017, with no limit on the publication date.

Hand searches were performed as follows: the scientific journal Medical Problems of Performing Artists (MPPA, until volume 24, issue 4 December 2009, after in MEDLINE) between February 13th and 27th, 2015 and actualized on December 7th, 2017 as well as the German journal Fachzeitschrift Musikphysiologie und Musikermedizin (FMM, years 1994-1999 were excluded, because online access was not available), the official scientific publication of the German Association for Music Physiology and Musicians' Medicine (DGfMM), between February 28th and March 8th 2015 and actualized on December 7th, 2017. Reference lists of seven identified systematic reviews (Zaza 1998; Bragge et al. 2006; Wu 2007; Baadjou et al. 2016; Jacukowicz 2016; Kok et al. 2016; Vervainioti and Alexopoulos 2015) were searched for further studies. The search strategy followed three guidelines: the study population, investigated MCD and study design. The search strategy is shown in Appendix 1.

\section{Data collection and analyses}

\section{Study selection}

The titles and abstracts of the identified studies were screened for eligibility by two authors (KN, GR). Studies not meeting the inclusion criteria were excluded. The remaining studies were evaluated for inclusion via full-text reviews by two of the four authors (KN, GR, AS, AB). During the fulltext review, a predefined checklist form was completed as reported in "Assessment of study quality and dealing with missing data". For articles not published in English or German, a translated summary was examined for eligibility criteria. Discrepancies in the study selection between authors were resolved in a consensus conference.

\section{Data extraction}

Data extraction was performed by two of the four authors (KN, GR, AS, AB) using standardized data extraction forms as reported below. Discrepancies in the data extraction between the reviewing authors were resolved by discussion and consensus.

\section{Assessment of study quality and dealing with missing data}

Depending on the study design, the quality of studies can be assessed using various checklists or scores. A standard assessment tool is the Study Quality Assessment Tool of the National Heart, Lung, and Blood Institute (NHLBI). It provides a thorough assessment of the quality of studies in all medical disciplines. It can be applied to observational studies such as intervention studies and seemed appropriate to be extended by a scoring system for comparison purposes in this review.

To apply comparable quality assessment tools to all of the included study designs, the reviewing authors developed a modified version of the "Study Quality Assessment Tool" from the National Heart, Lung, and Blood Institute. The "Quality Assessment of Observational Cohort and CrossSectional Studies," "Quality Assessment of Before-After (Pre-Post) Studies With No Control Group" and the "Quality Assessment of Controlled Intervention Studies" (NHLBI) were adapted by adding items to the quality assessment tools about the Critical Appraisal Skills Program (CASP), the "CASP-Checklists" (CASP 2013) and the "Methodology Checklists" of the Scottish Intercollegiate Guidelines Network (SIGN). The instructions for application were predefined and adapted in a consensus by all authors. A scoring system was implemented in which one point was given for 
each item on the form that was fulfilled by the study and one point was subtracted for each item that was not fulfilled. If an item was not applicable to a study, zero points were given. If a study did not report on the requested item, one point was subtracted for that item. The total score was calculated by adding the individual points without weighting for single items. The total number of possible points varied for each evaluation instrument depending on the type of study. Case-control studies could reach a maximum of 14 points, cohort studies and cross-sectional studies could reach a maximum of 16 points, controlled intervention studies could reach a maximum of 18 points and pre-post studies without a control group could reach a maximum of 15 points (Appendix 2). Total scores were not comparable across different types of study designs. The described modified quality assessment tools were used for the quality assessments of the individual studies by two of the four authors (KN, GR, AS, AB). Disagreements over study quality assessment and scoring were resolved by discussion and consensus. If multiple publications were produced from one study, only one quality assessment was performed based on the publication we considered to be the most comprehensive and with the highest methodological quality.

\section{Data synthesis}

The extracted information included the (1) authors, (2) date of publication, (3) population(s) studied, (4) number of participants, (5) exposure or interventions relevant to the review questions, (6) randomization status; (7) outcomes and (8) results. If these data were not provided, they were marked as missing. The results of individual studies were reported as frequencies in percentages, effect sizes, mean values with standard deviations or standard errors, significance values, odds ratios and confidence intervals. With the exception of percentages, no calculations were made based on the values provided. If a study did not provide quantitative data in numbers, the narratively described results were used.

\section{Results}

\section{Overview of selected studies}

The search strategy identified 2074 articles. Figure 1 depicts the results of the individual steps of the selection process. In total, 109 articles were included in the study, 28 of which were case studies and 81 of which were articles for quality assessment. The 81 articles assessed for methodological quality included 1 case-control study, 6 cohort studies, 62 cross-sectional studies, and 12 interventional studies ( 9 controlled intervention studies and 3 pre-post studies without control groups).
The characteristics of the included studies are shown in Tables 1 through 6 . Across all study types, we found that the different terms used and the definitions of outcome parameters significantly limited the comparability of the included studies. In the "outcomes" columns in Tables 1 through 5, the individual terms used by the studies are cited. Even the abbreviation "PRMD" is used and defined heterogeneously.

The term "PRMD" as "performance-related musculoskeletal disorders" was used in seven publications (Ackermann et al. 2002b, 2011, 2012; Chan et al. 2013; Chan et al. 2014; Khalsa and Cope 2006; Khalsa et al. 2009). Among these, two intervention studies defined performance-related musculoskeletal disorders according to Zaza and Farewell as "any pain, weakness, numbness, tingling or any other symptoms that interfere with your ability to play your instrument at the level you are accustomed to. This definition does not include transient aches or pains" (Ackermann et al. 2002b; Chan et al. 2014; Zaza and Farewell 1997). One study defined the same term as "a musculoskeletal disorder was considered performancerelated if the injury occurred during or immediately after playing and the musician specified that playing the instrument was the main contributor to their injury"(Chan et al. 2013). The term "PRMD" as "performance-related musculoskeletal pain disorders" was applied in three other publications (Kenny and Ackermann 2015; Ackermann et al. 2012; Kenny et al. 2016) that used the definition based on Zaza and Farewell (Zaza and Farewell 1997), as mentioned above. The term "PRMD" as "playing-related musculoskeletal disorders" was used in ten studies (Steinmetz et al. 2012; Arnason et al. 2014; Kim et al. 2012; KaufmanCohen and Ratzon 2011; Mishra et al. 2013; Kochem and Silva 2017; Monaco et al. 2012; Sousa et al. 2016; de Greef et al. 2003; Rickert et al. 2012). The definitions within the studies were heterogeneous; for example, in one study (Rickert et al. 2012), the term "PRMD" was used without further definition but was used synonymously with "injury" without the specific association that the PRMD was related to playing an instrument. A broad variety of additional terms were applied, sometimes only in one or a few studies (see Tables 1 through 5).

\section{Case-control study}

The included case-control study (Sakai and Shimawaki 2010) investigated the indices of hand and movement angles in 220 pianists in Japan with overuse disorders and 62 unaffected pianists as controls. The authors reported that epicondylitis, muscle pain in the forearm and hypothenar region, De Quervain's tendinitis and distal tendinitis were correlated with variable parameters of small hand size (Table 1). 
Fig. 1 Study selection process

Articles identified $(n=2074)$
Articles identified in digital litera

Articles identified in digital literature databases $(n=1.954)$ :

CINAHL $(n=252)$

$\operatorname{ERIC}(n=10)$

Medline and EMBASE $(n=1.504)$

PsycArticles and Psyclnfo $(n=188)$

Hand search and Web search of professional journals (Fachzeitschrift Musikphysiologie und Musikermedizin (FMM) and Medical Problems of Performing Artists $(n=120)$

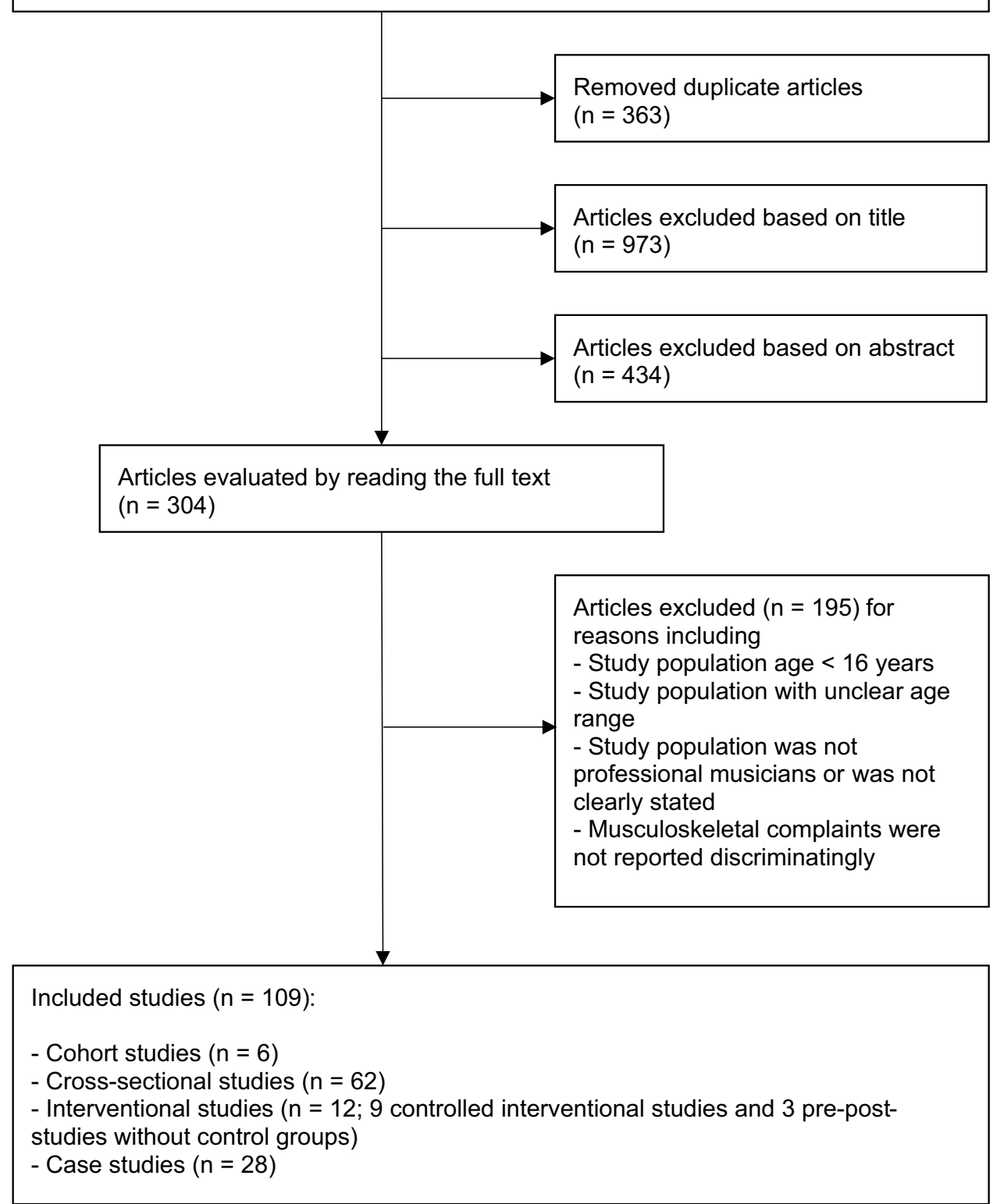

\section{Quality assessment of the case-control study}

The quality of the case-control study (Sakai and Shimawaki 2010) was assessed as a -3 (out of 14 possible points) due to relevant concerns in the study methodology, such as the absence of a sample size justification and not reporting the details of the study population, inclusion- or exclusion criteria or participant selection (randomly or as a convenience sample). Furthermore, there was no reporting on the blinding of the assessors of exposure/risk factors. 


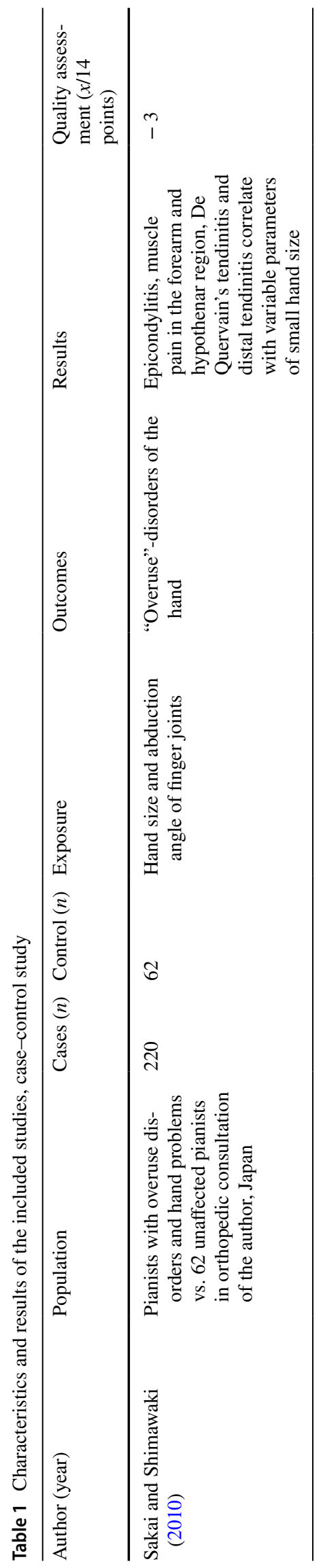

\section{Cohort studies}

Three of the six cohort studies were retrospective evaluations of patient records from a university's health service, one of which was a follow-up of another study (Manchester and Flieder 1991; Manchester 1988; Manchester and Lustik 1989). The incidence of playing-related disorders of the upper limb and/or hand was reported as 8.5 episodes per 100 music students per year, and $16 \%$ had persistent complaints. Risk factors were not evaluated. The fourth cohort study investigated the incidence of work-related musculoskeletal disorders in music teachers and did not identify an elevated arm position of $>30^{\circ}$ as a potential risk factor (FjellmanWiklund and Sundelin 1998). Another cohort study found that there is generally a moderate degree of disability and pain in violinists, cellists and pianists, though cellists had more disability and pain than the other types of musicians (Piatkowska et al. 2016). The sixth cohort study found that $29 \%$ of music students complain about playing-related health issues (mixed somatic and psychological) in their 1st year of study (Nusseck et al. 2017). Details are shown in Table 2.

\section{Quality assessment of the cohort studies}

The quality assessment scores of the six cohort studies were between -11 and 10 out of 16 possible points, mainly due to significant methodological concerns in most of the studies. Only three of the studies (Fjellman-Wiklund and Sundelin 1998; Nusseck et al. 2017; Piatkowska et al. 2016) had clearly defined study populations. None of the studies reported sample size calculations, and only one study (Nusseck et al. 2017) prospectively measured risk factors. However, three studies applied validated outcome measurements (Nusseck et al. 2017; Piatkowska et al. 2016; Kuorinka et al. 1987; Fjellman-Wiklund and Sundelin 1998).

\section{Cross-sectional studies}

We found 62 cross-sectional studies (see Table 3).

\section{Outcome measures used in cross-sectional studies}

MCDs in the cross-sectional studies were measured with different instruments and used different definitions and questionnaires that to our knowledge, were often not validated (Abréu-Ramos and Micheo 2007; Ackermann et al. 2011; Arnason et al. 2014; Blackie et al. 1999; Chan et al. 2013; Crnivec 2004; Davies and Mangion 2002; De Smet et al. 1998; Fishbein et al. 1988; Fry 1986; Heredia et al. 2014; Hodapp et al. 2009; Kim et al. 2012; Kok et al. 2013; 2015; Kovero and Könönen 1995; Marques et al. 2003; Schäcke et al. 1986; Middlestadt and Fishbein 1989; Molsberger 1991; Papandreou and Vervainioti 2010; Raymond et al. 


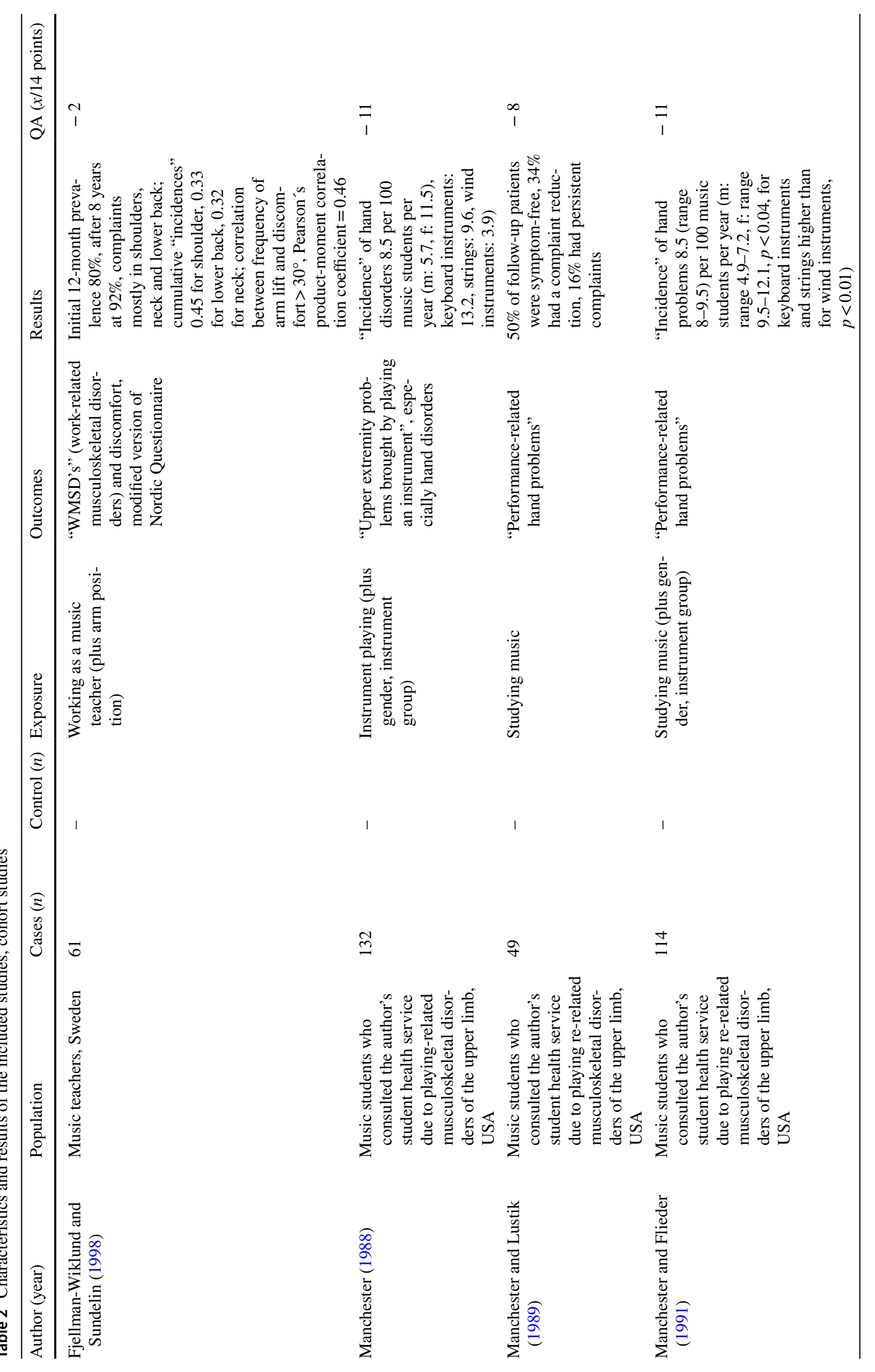




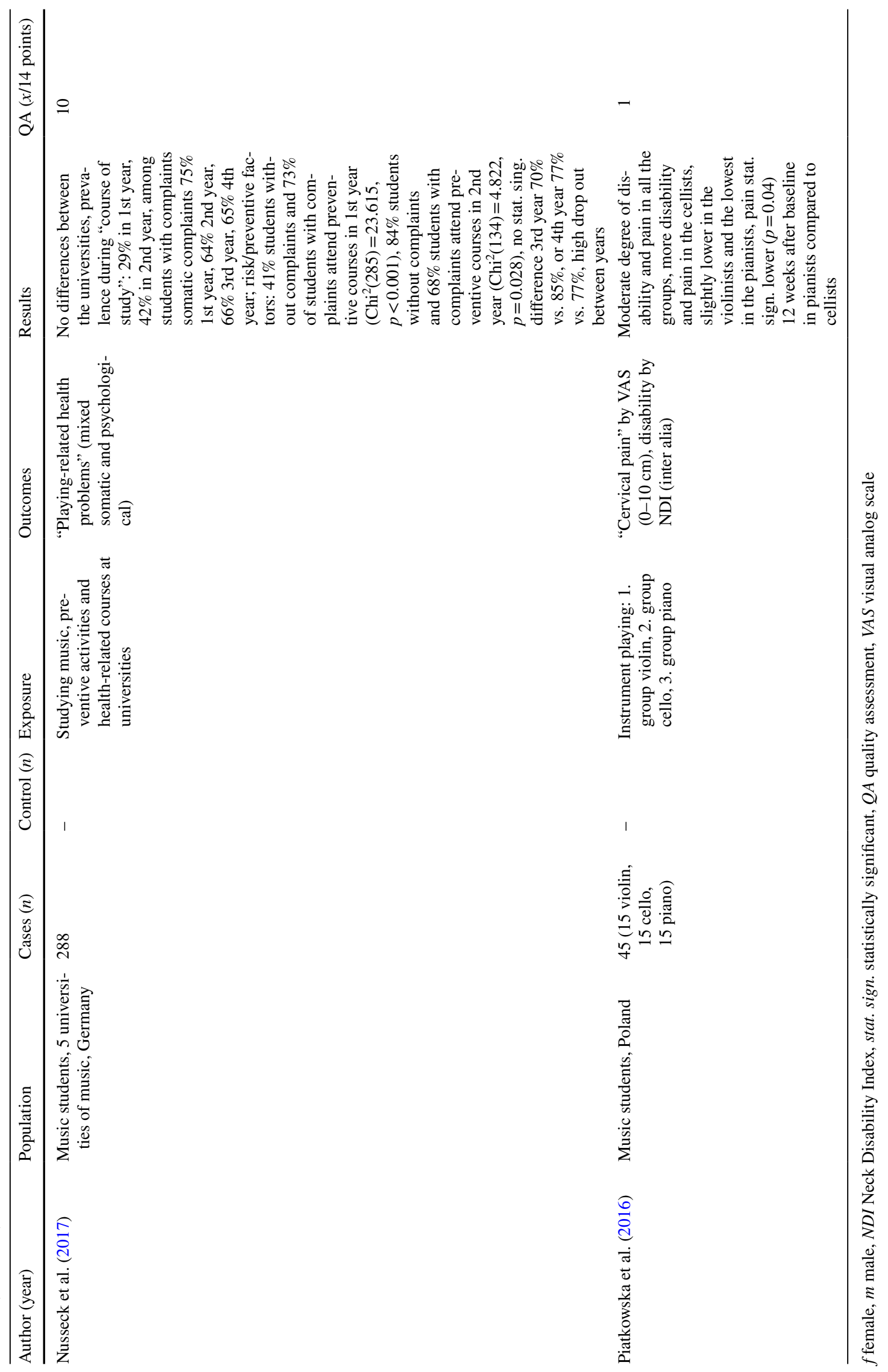




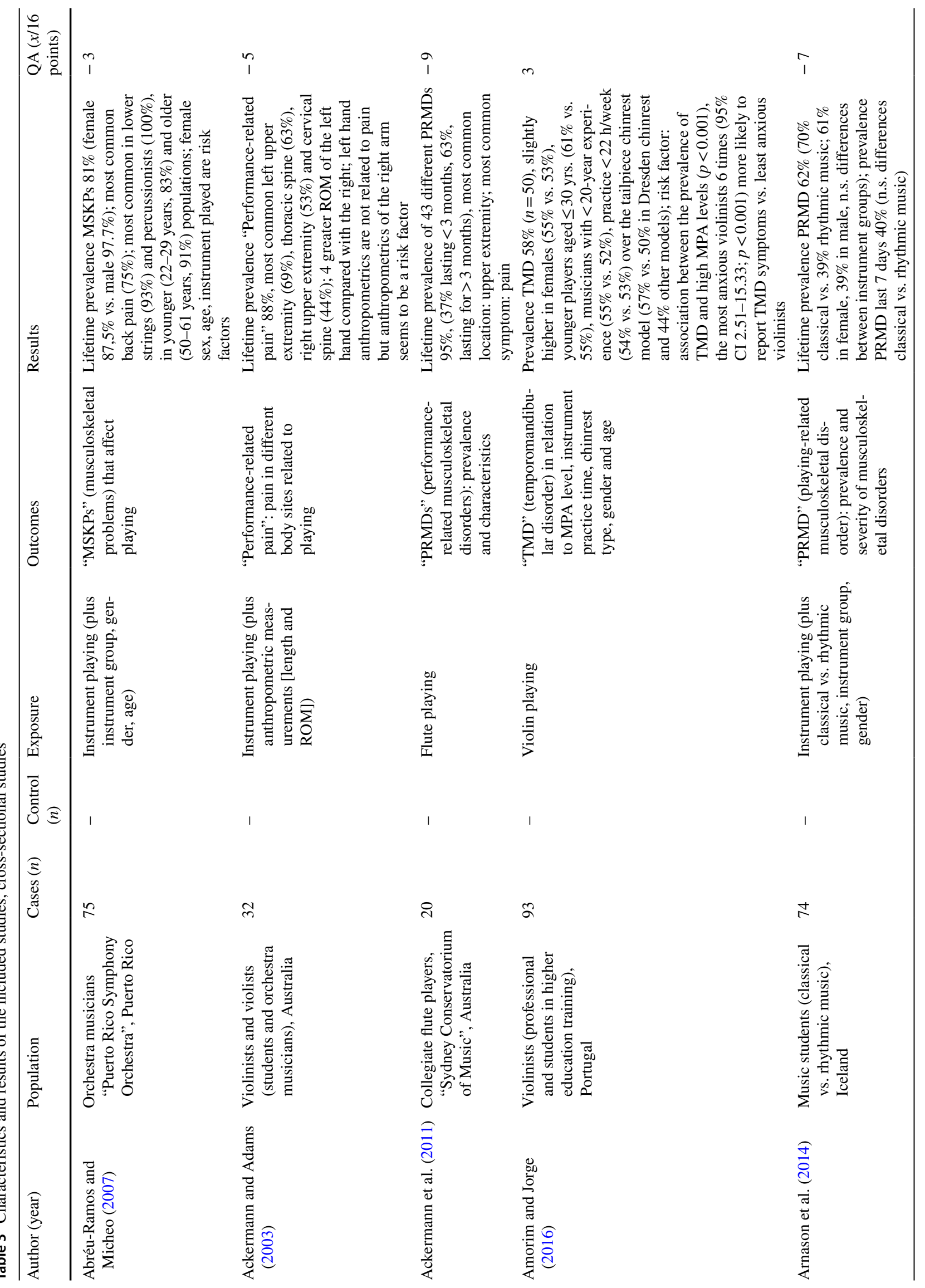




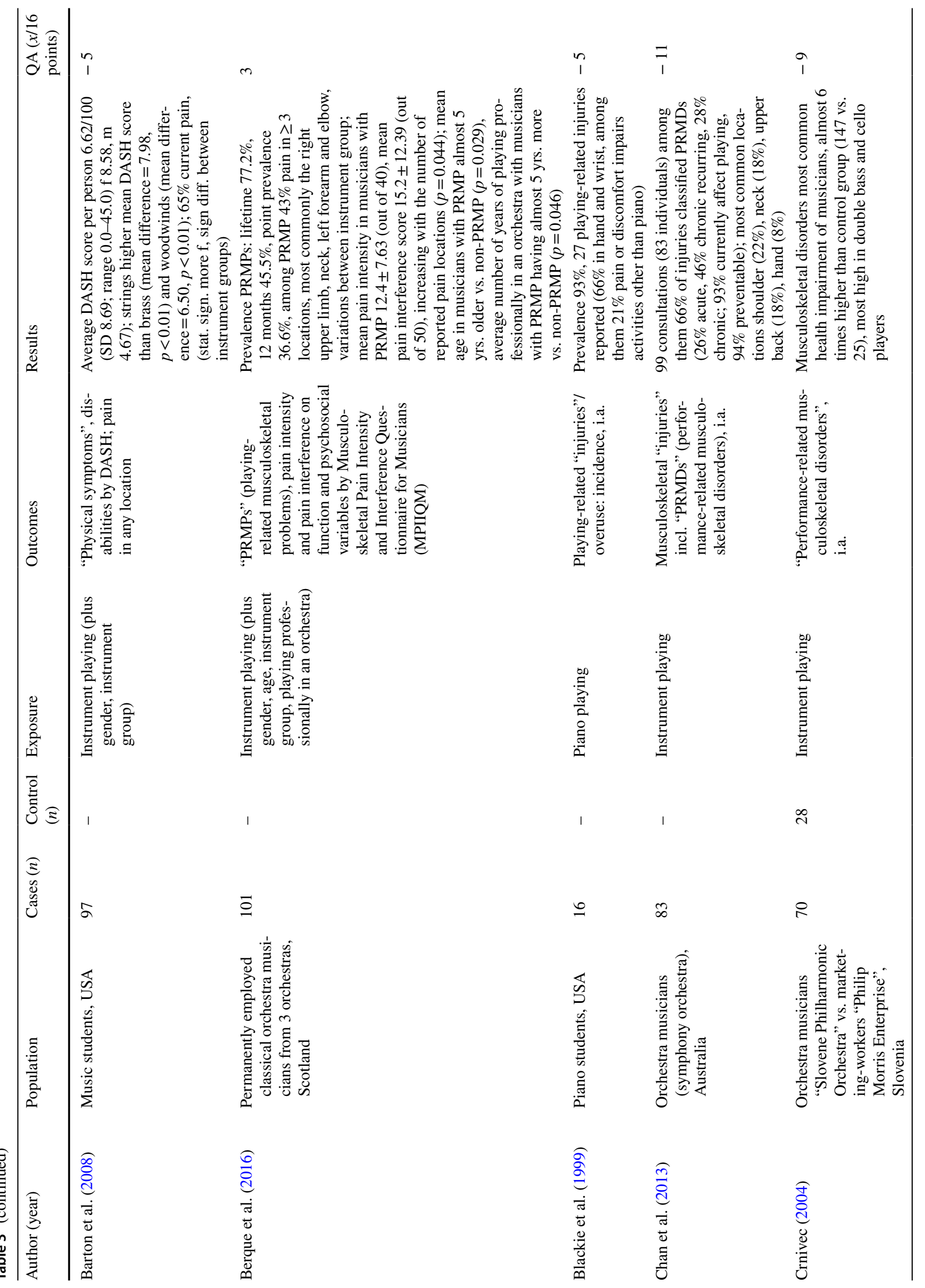




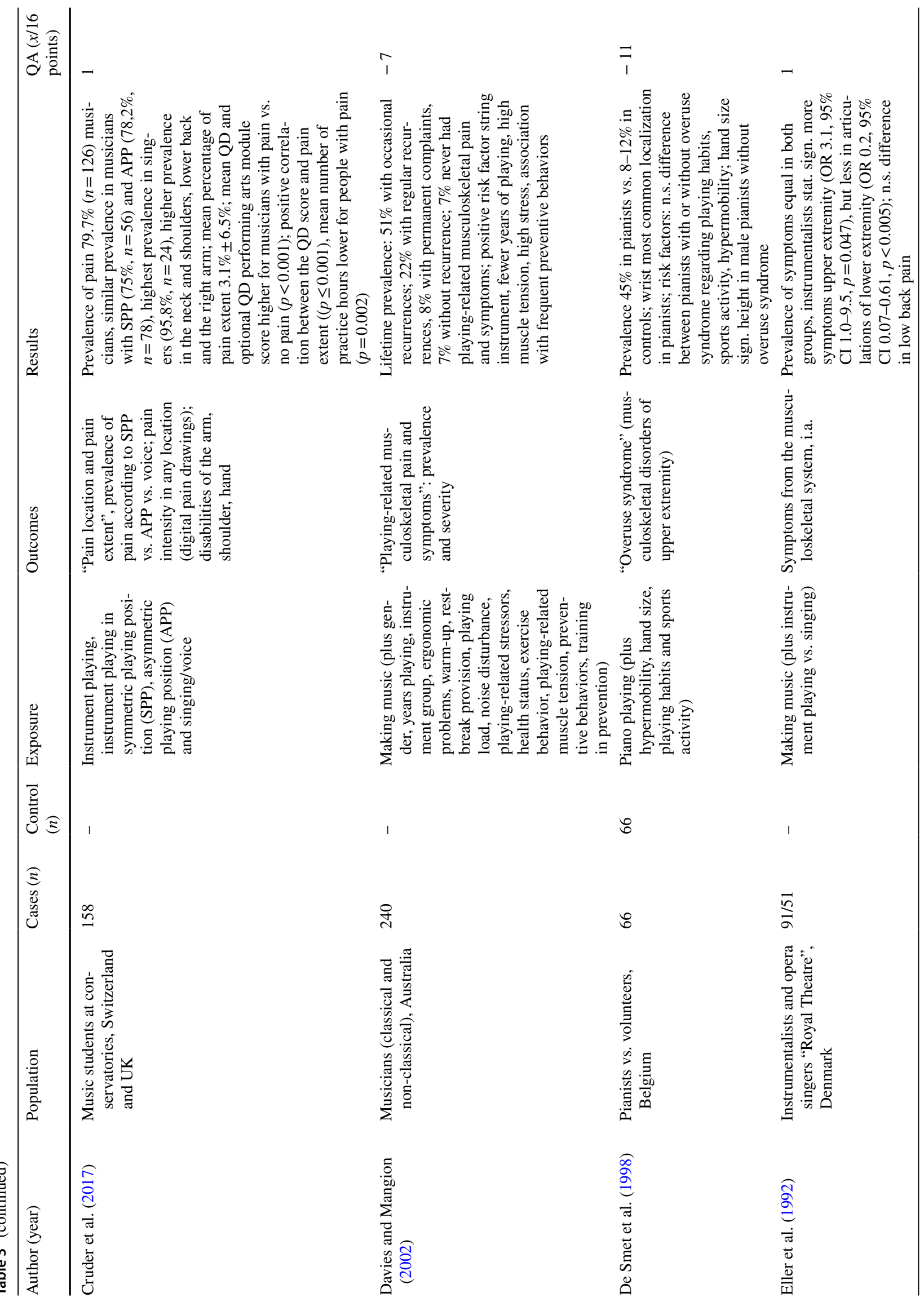




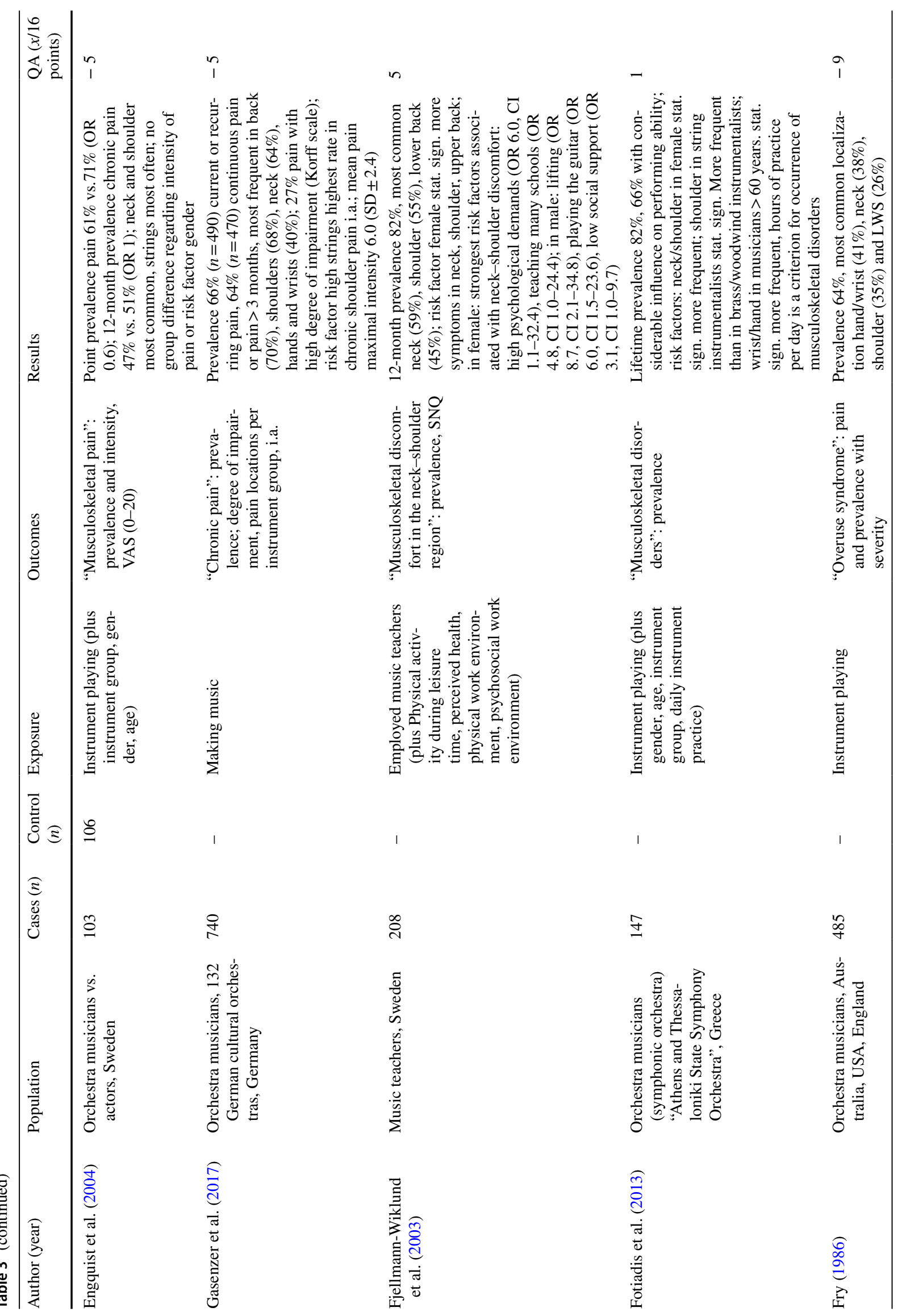




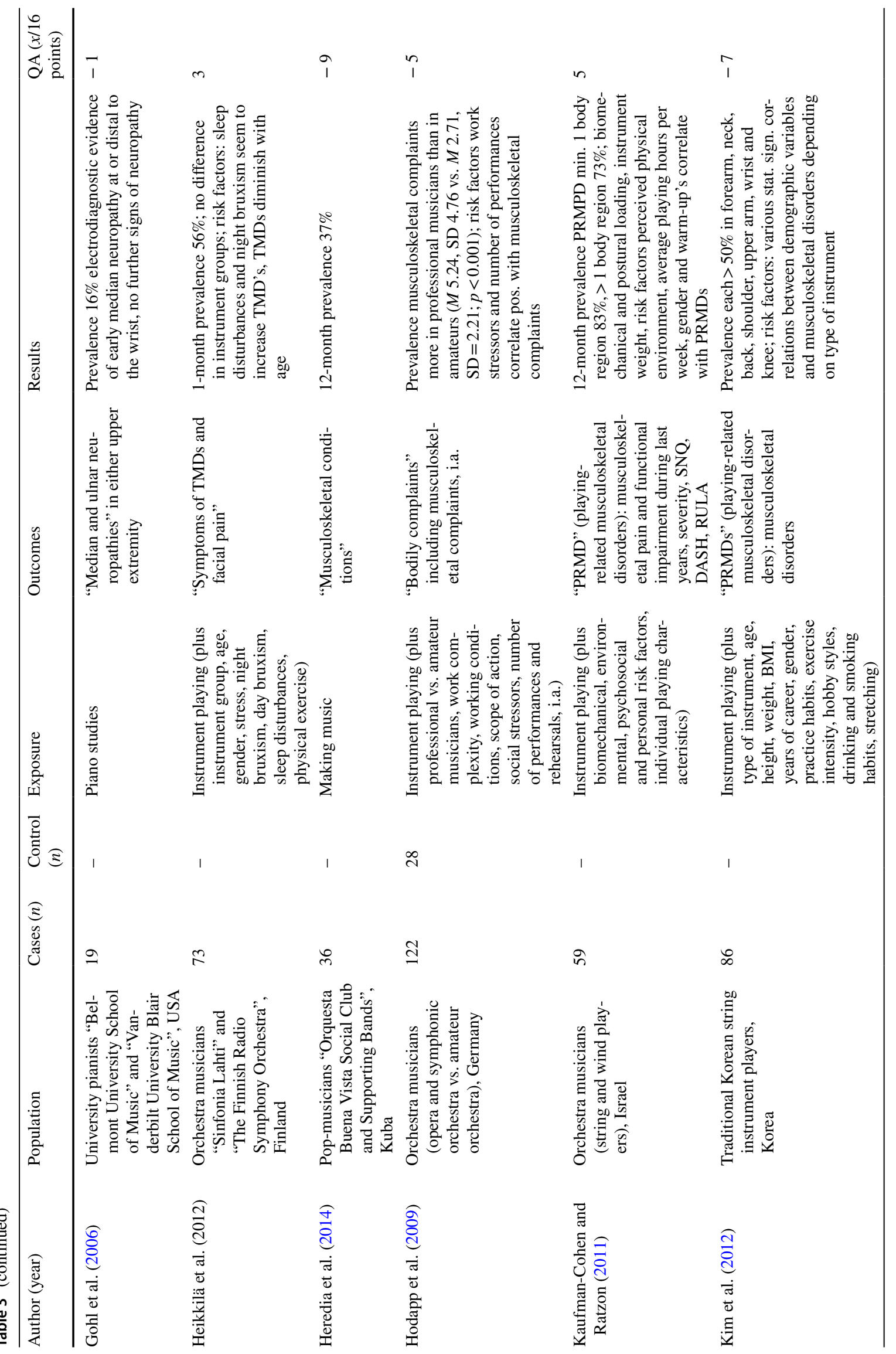




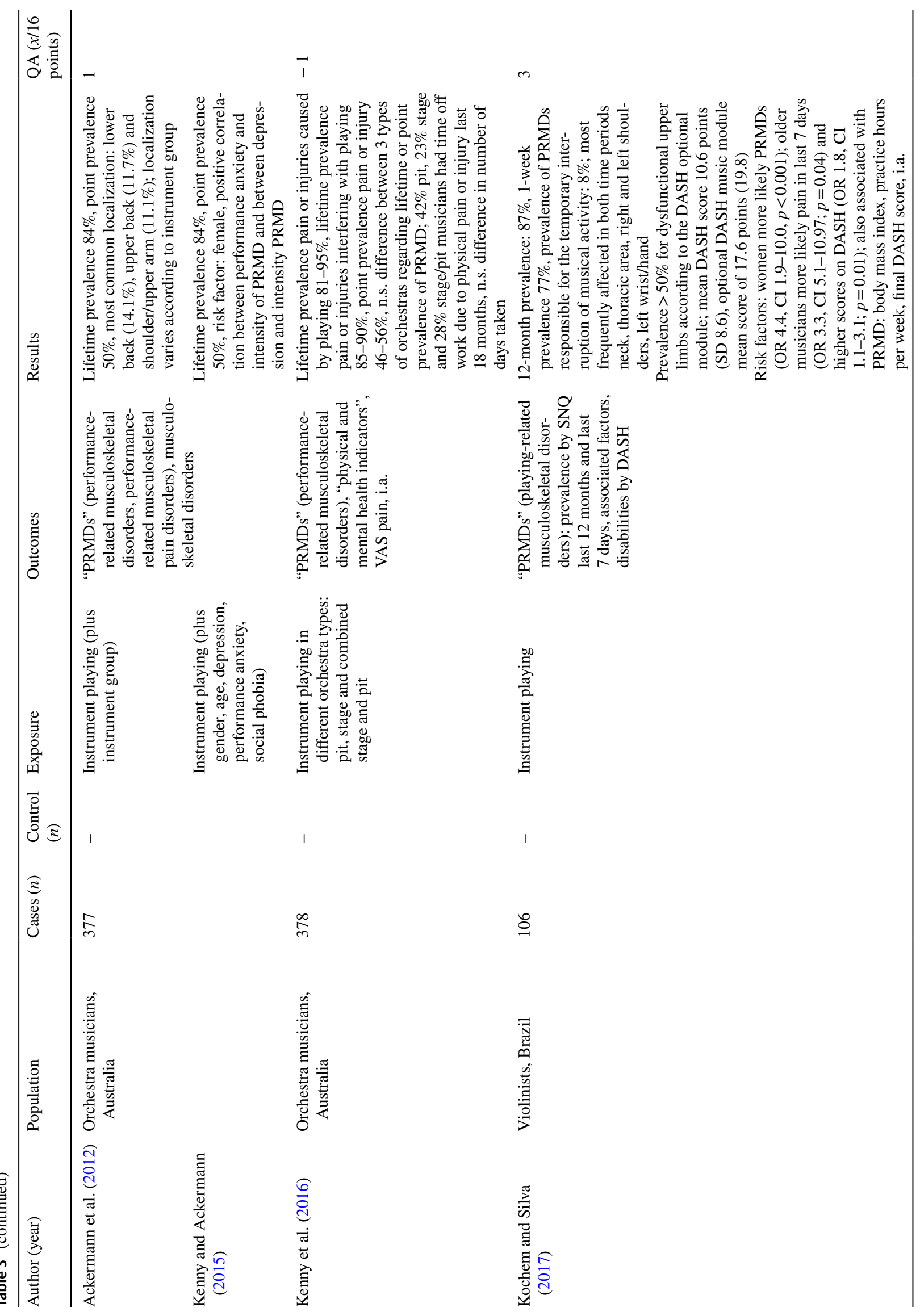




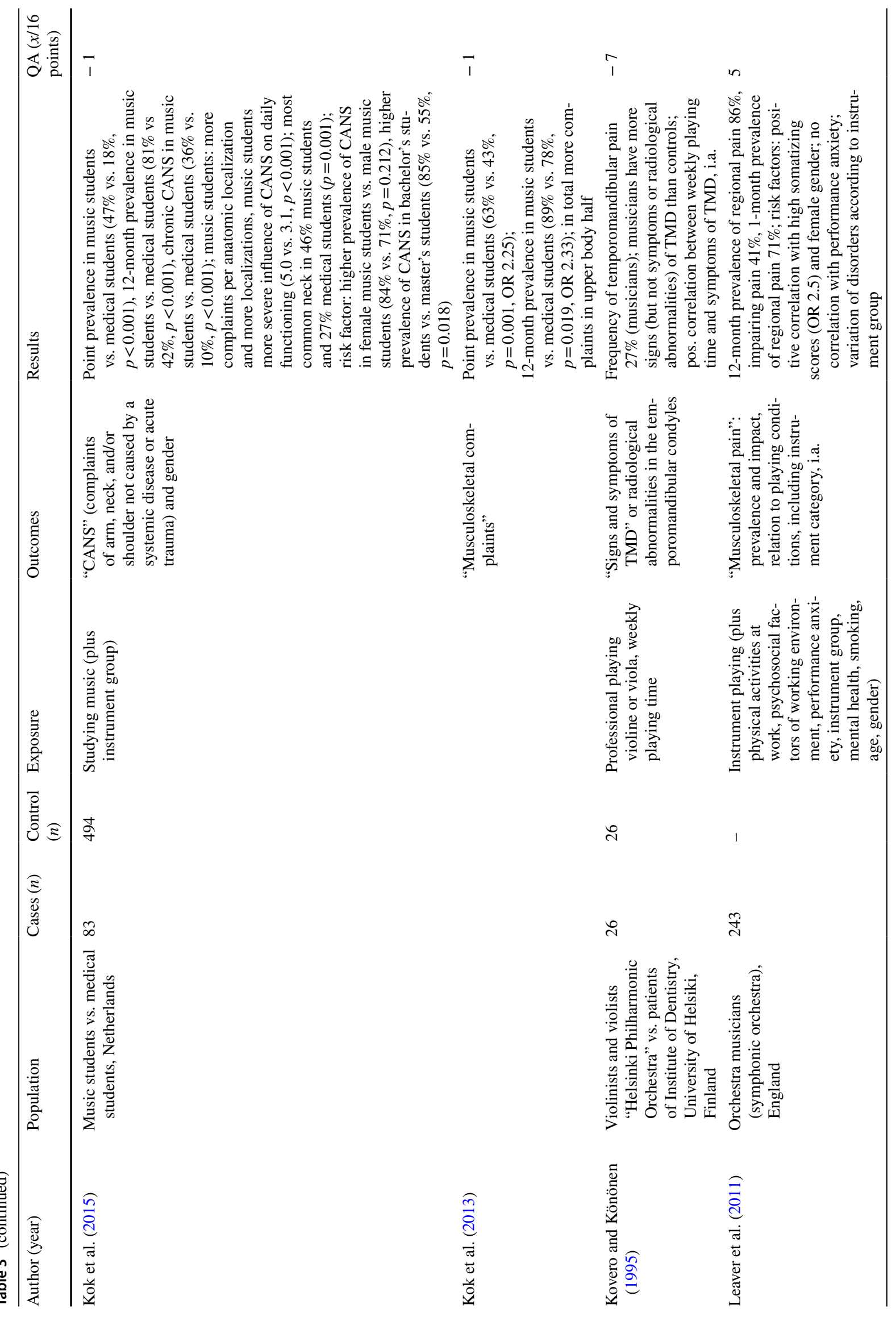




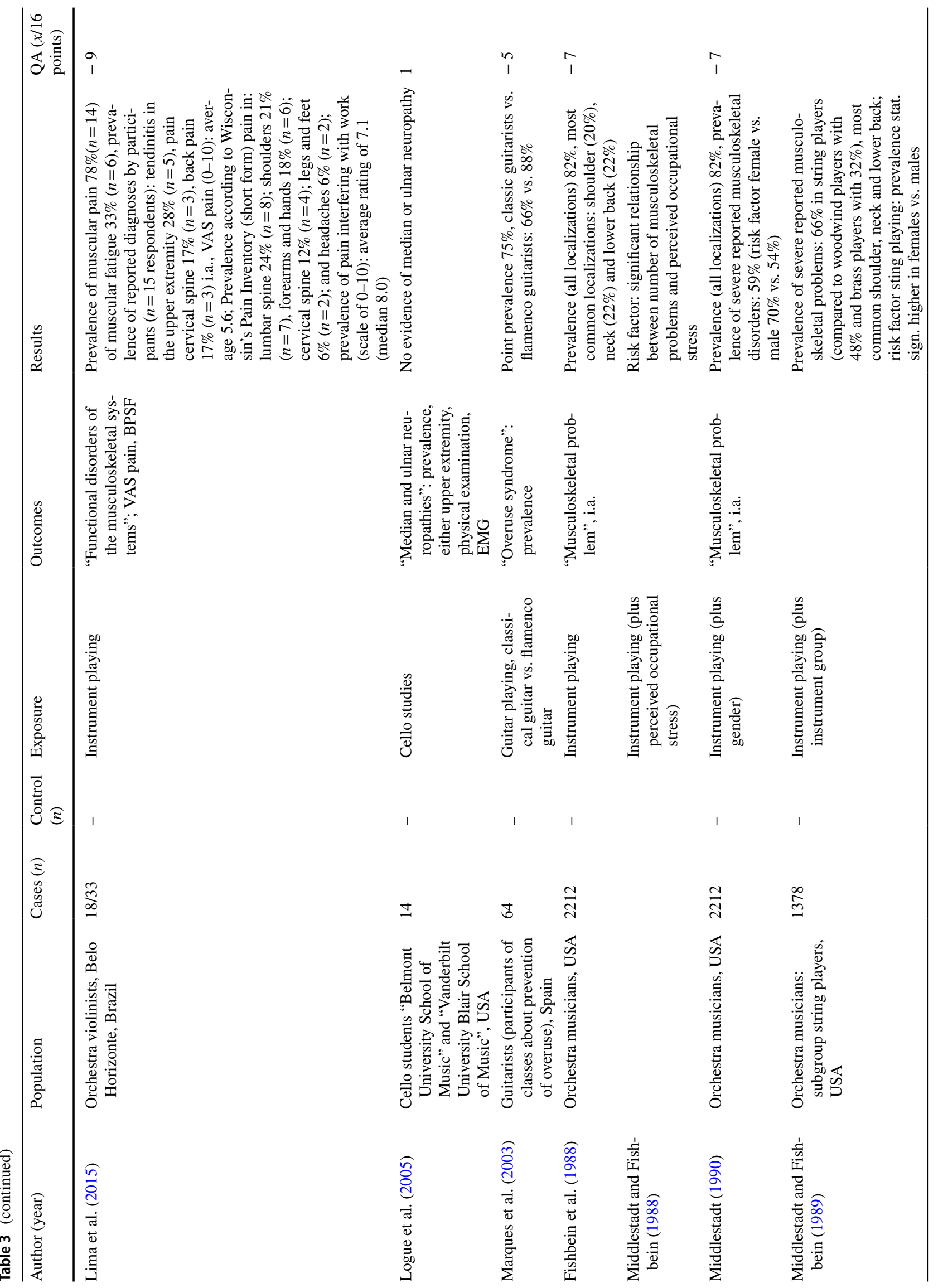




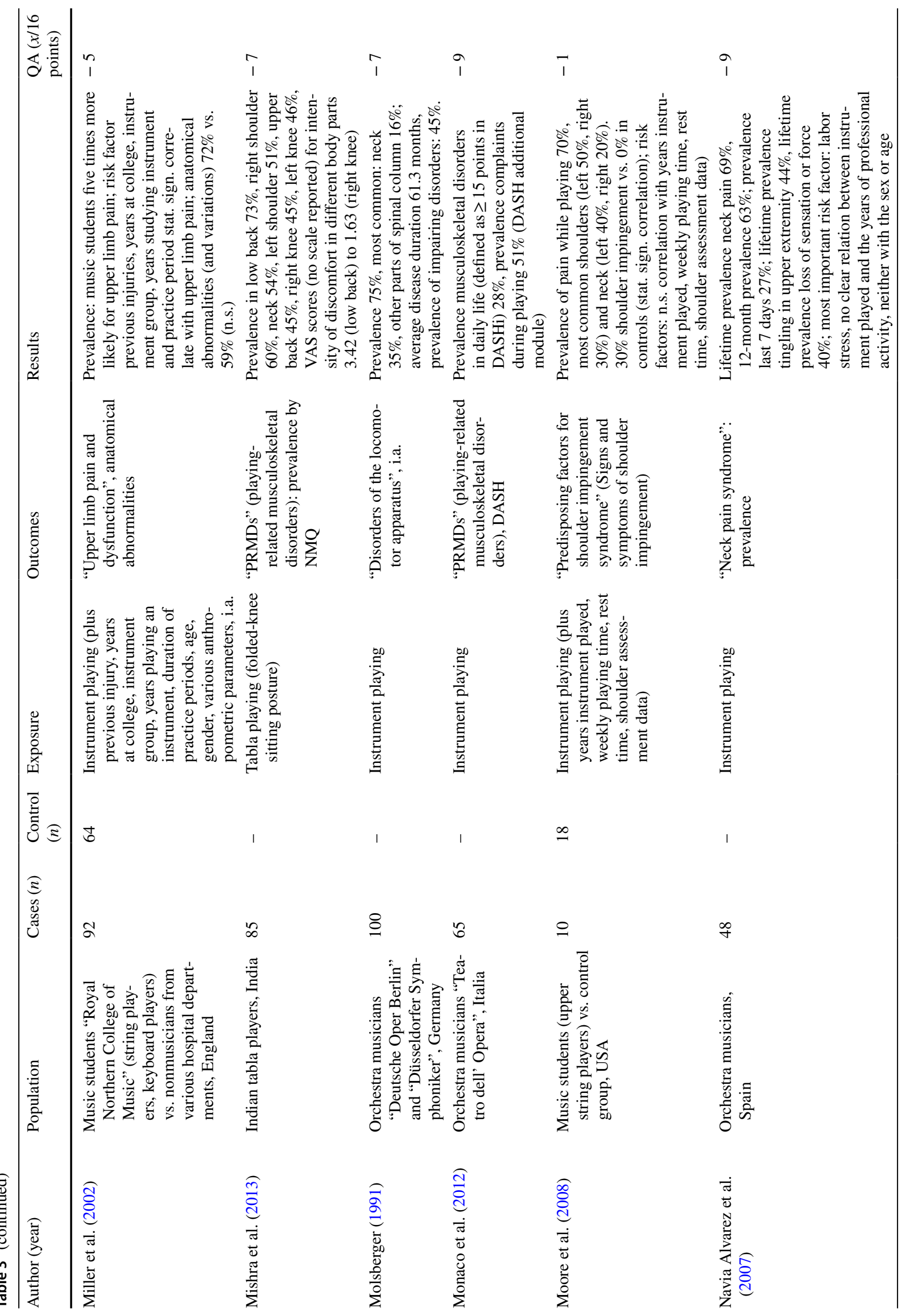




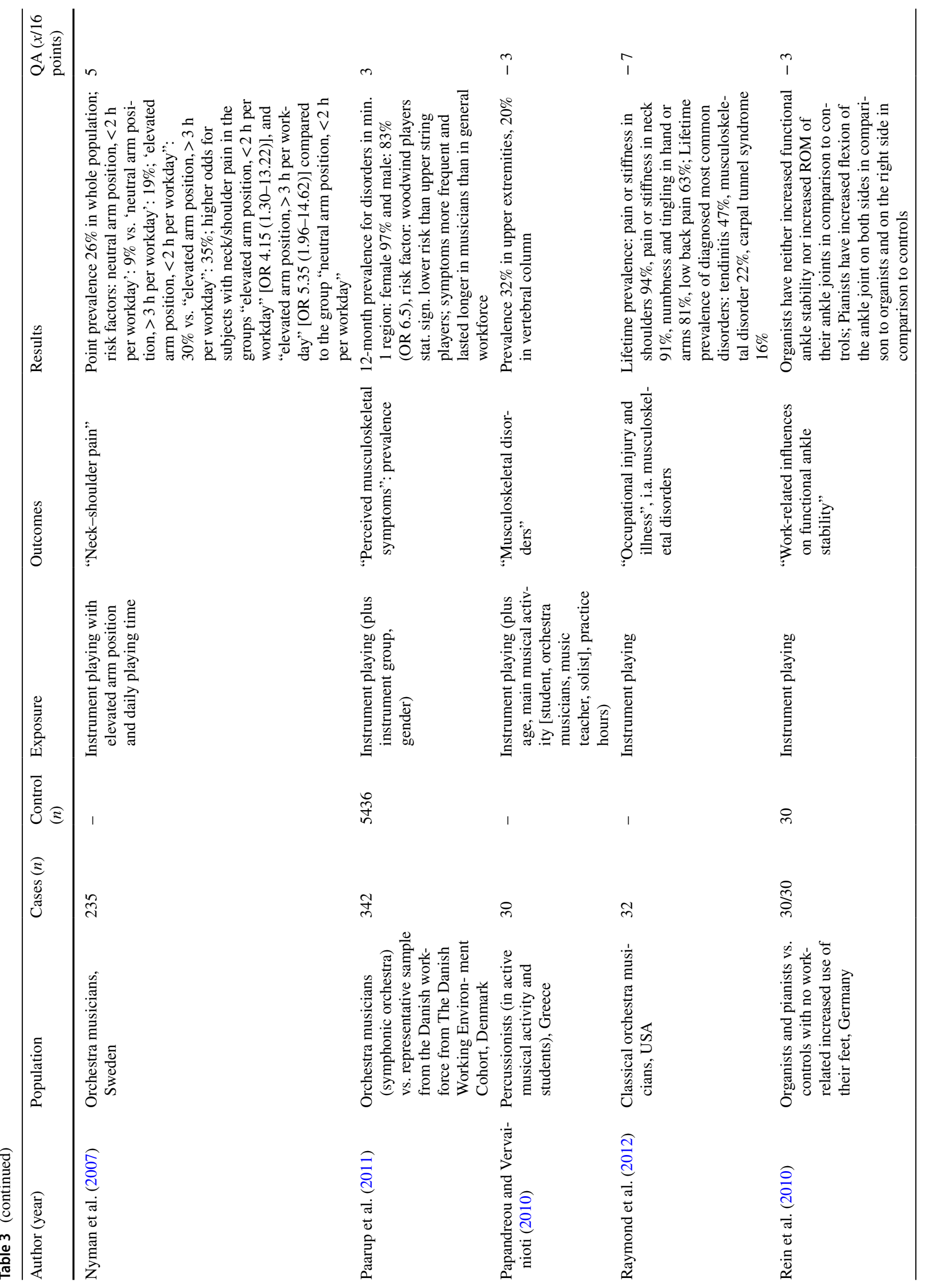




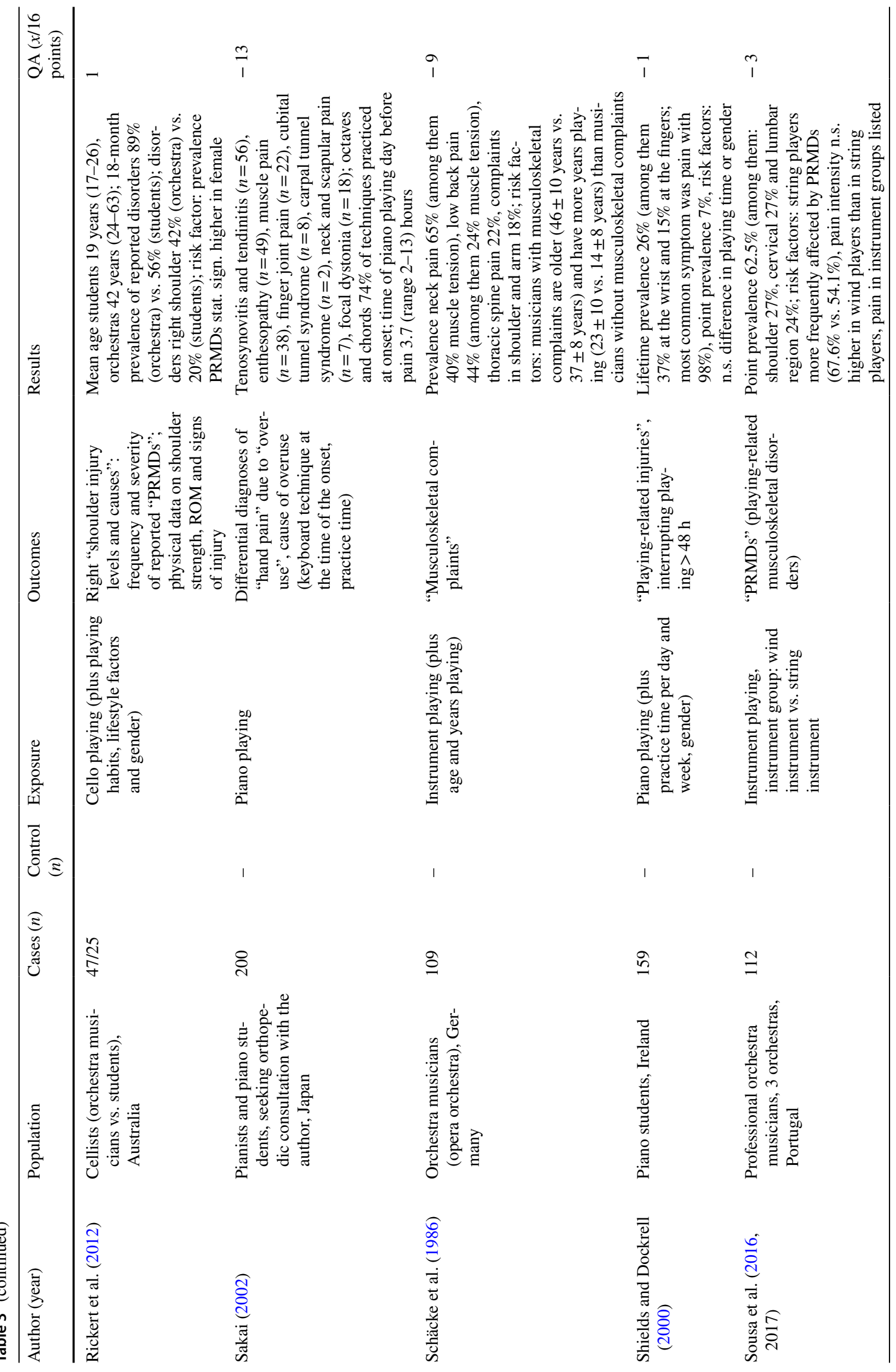




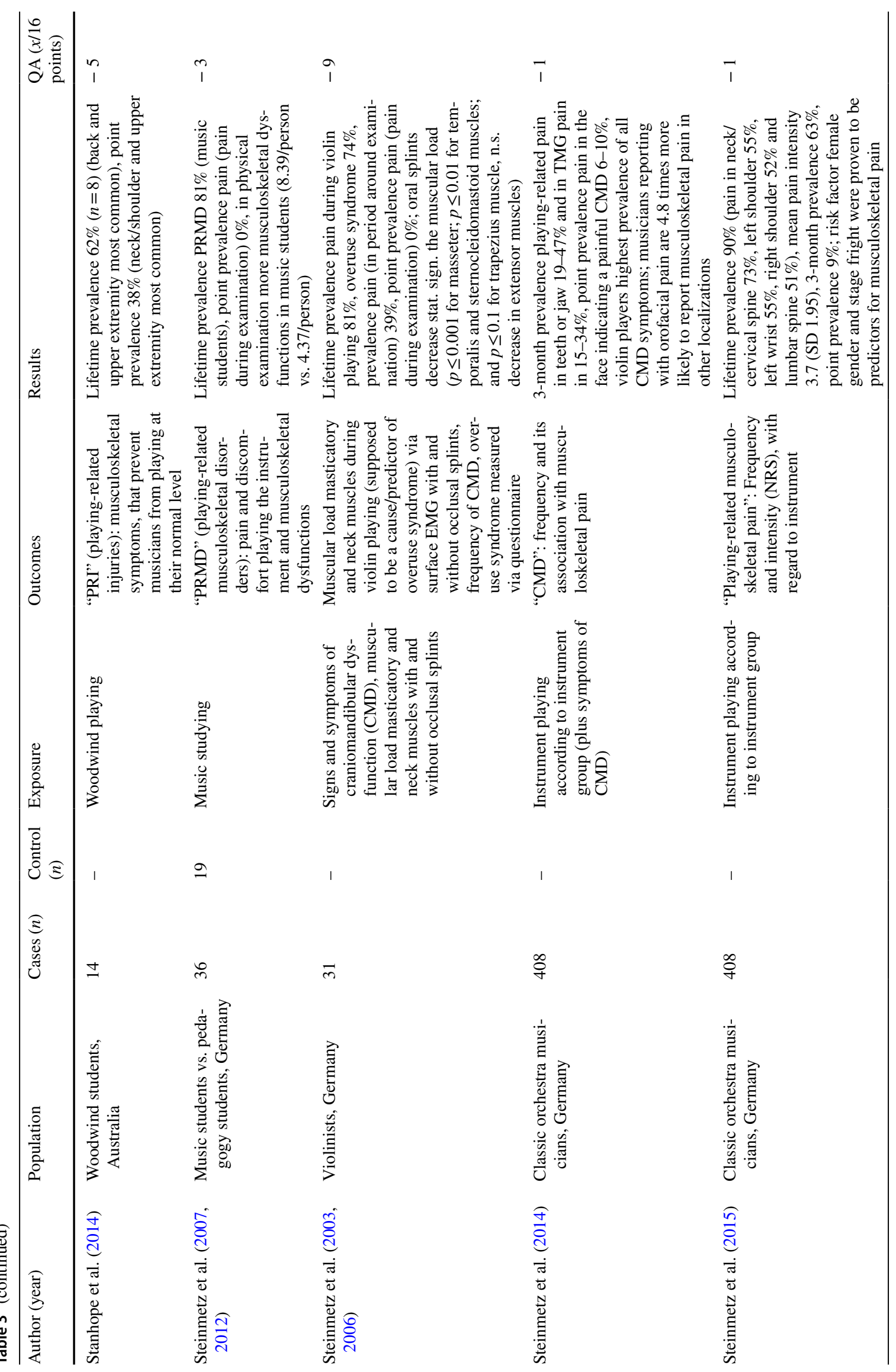




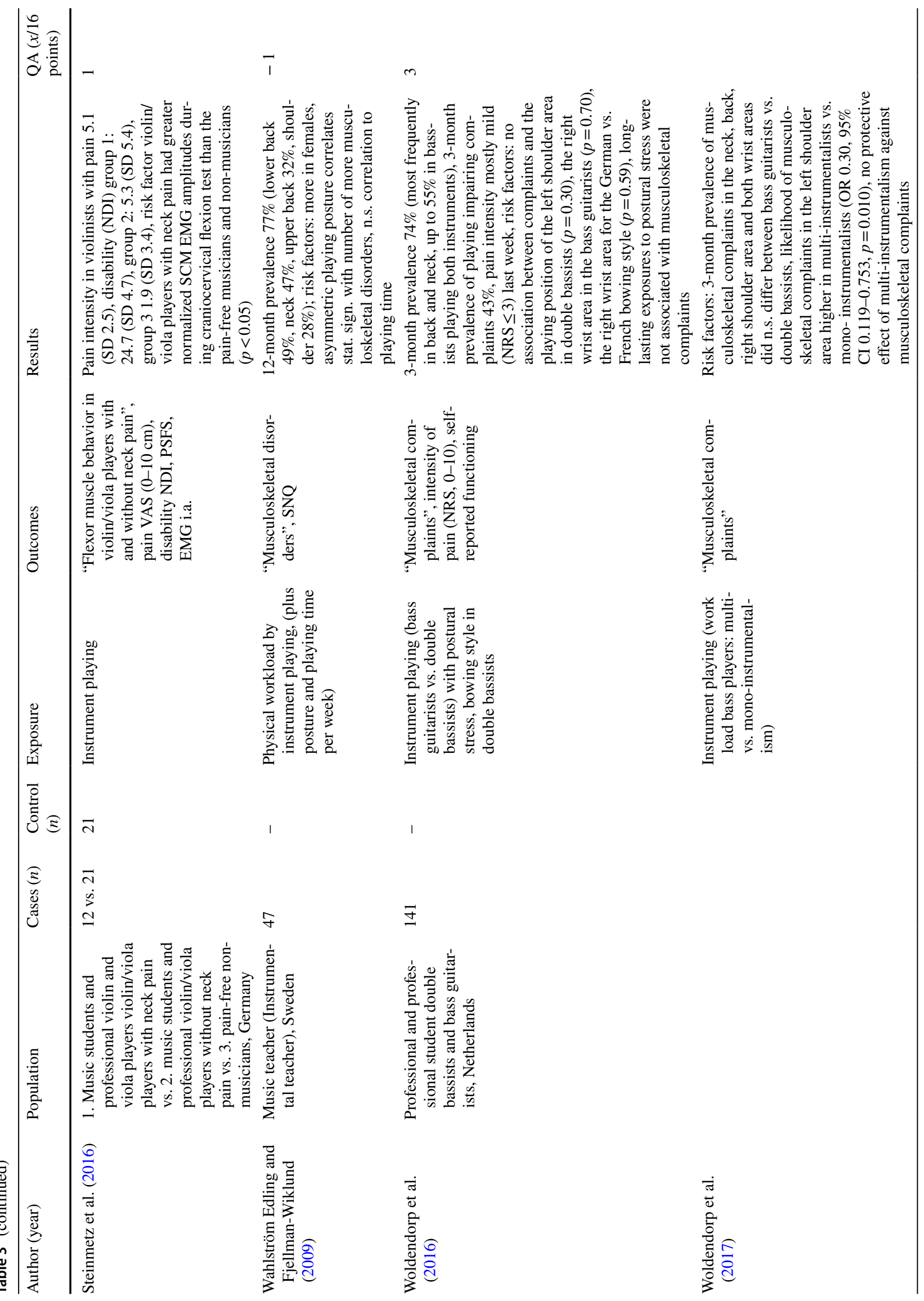




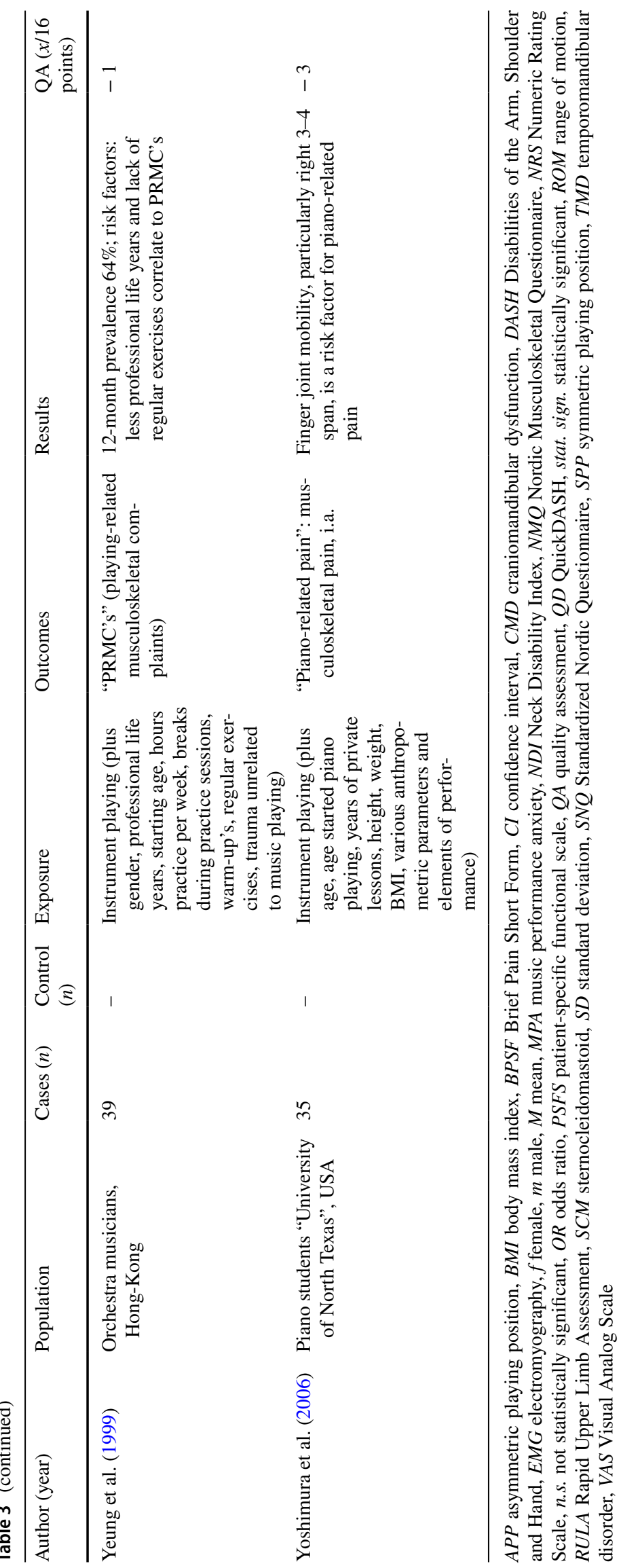


2012; Steinmetz and Möller 2007; Shields and Dockrell 2000; Sakai 2002).

\section{Period of time investigated in cross-sectional studies}

The time period of the measured MCD varied substantially between studies, ranging from whole lifetimes, years playing an instrument, the previous 1, 3, 12 or 18 months, the last 7 days or current complaints. For some publications, we could not find a specification of the exact time frame used by the study, f.e. (Lima et al. 2015; Blackie et al. 1999; Crnivec 2004; De Smet et al. 1998; Eller et al. 1992; Fishbein et al. 1988; Fry 1986; Schäcke et al. 1986; Hodapp et al. 2009; Kim et al. 2012; Kovero and Könönen 1995; Middlestadt 1990; Middlestadt and Fishbein 1988, 1989; Molsberger 1991; Papandreou and Vervainioti 2010).

\section{Prevalence reported in cross-sectional studies}

Due to substantial heterogeneity among the measured complaints, a comparison of prevalence and correlations to the MCD was not feasible. In the included studies, the prevalence of MCDs ranged from point prevalence $0 \%$ in one small study (Logue et al. 2005) to 12-month prevalence 97\% in a study of female orchestra musicians (Paarup et al. 2011). However, within the four studies that received a quality assessment of 5, the 12-month prevalence ranged from 82 to $86 \%$ (Leaver et al. 2011; Kaufman-Cohen and Ratzon 2011; Fjellmann-Wiklund et al. 2003), with $26 \%$ of musicians reporting current complaints (Nyman et al. 2007).

\section{Risk factors reported in cross-sectional studies}

The four studies with the best quality assessments reported playing with an elevated arm position as a risk factor for neck-shoulder pain (Nyman et al. 2007). Neck-shoulder discomfort in female music teachers was correlated with high psychological demands and teaching at multiple schools, whereas in male music teachers, it was associated with lifting, playing the guitar and low social support (FjellmannWiklund et al. 2003). In symphony orchestras, MCD tended to be more frequent among women, in musicians experiencing low mood and in those with high somatizing scores. Only weak associations were observed with psychosocial work stressors and performance anxiety (Leaver et al. 2011). In musicians who play string instruments, the odds of wrist/ hand pain were 2.9-fold higher than for those who play wind instruments (Leaver et al. 2011). In contrast, another study found that in classical musicians, string musicians showed higher PRMD scores than woodwind and brass players. Furthermore, the study found a correlation with biomechanical risk factors, perceived physical environment risk factors, instrument weight and average number of hours played per week (Kaufman-Cohen and Ratzon 2011). However, crosssectional studies have low validity for verifying risk factors such as exposure time, and the occurrence of outcomes cannot thus be properly measured.

\section{Quality assessment of cross-sectional studies}

The quality scores of the 62 cross-sectional studies were between -13 and 5 out of 16 possible points, with significant methodological concerns existing in the studies. Only one study (Nusseck et al. 2017) utilized a time frame that could reliably measure the association between the exposure and outcome, although several studies explicitly looked for risk or predicting factors. No studies reported the blinding of outcome measures. Sample size calculations were reported in only two of the studies (Kochem and Silva 2017; Kaufman-Cohen and Ratzon 2011). Frequent concerns included the objectivity, reliability and validity of the outcome and exposure measurement tools. Often, no confounders were assessed, and only a few studies assessed at least some important confounders (Eller et al. 1992; Fjellmann-Wiklund et al. 2003; Leaver et al. 2011; Nyman et al. 2007; Kok et al. 2015; Nusseck et al. 2017; Piatkowska et al. 2016; Woldendorp et al. 2016, 2017).

\section{Intervention studies}

\section{Study designs and methods of the interventional studies included}

Three of the 12 intervention studies were performed using pre-post study designs without a control group (Table 4). One of these three studies compared two different interventions, (strength vs. endurance training) stratified by instrument played, but further information on randomization was not provided (Ackermann et al. 2002b). The other nine interventions used controlled designs (Table 5). Seven of the 12 studies were randomized controlled trials. In one partially blind study, playing under the intervention or control condition was randomized (Ackermann et al. 2002a). In one study with a three-armed design, participants in the two intervention groups were randomized, but the control group was recruited separately (Khalsa et al. 2009). In one non-randomized study, allocation of the nine eligible orchestras followed geographical criteria; the six orchestras that were geographically closest to each other were selected as interventional orchestras, while the remaining three served as control orchestras (Brandfonbrener 1997). The second non-randomized study was a pilot study for a partially randomized trial that was conducted later. The pilot recruited its control group separately due to a low number of participants (Khalsa and Cope 2006; Khalsa et al. 2009). Two publications about Tuina treatment appeared to be drawn from 


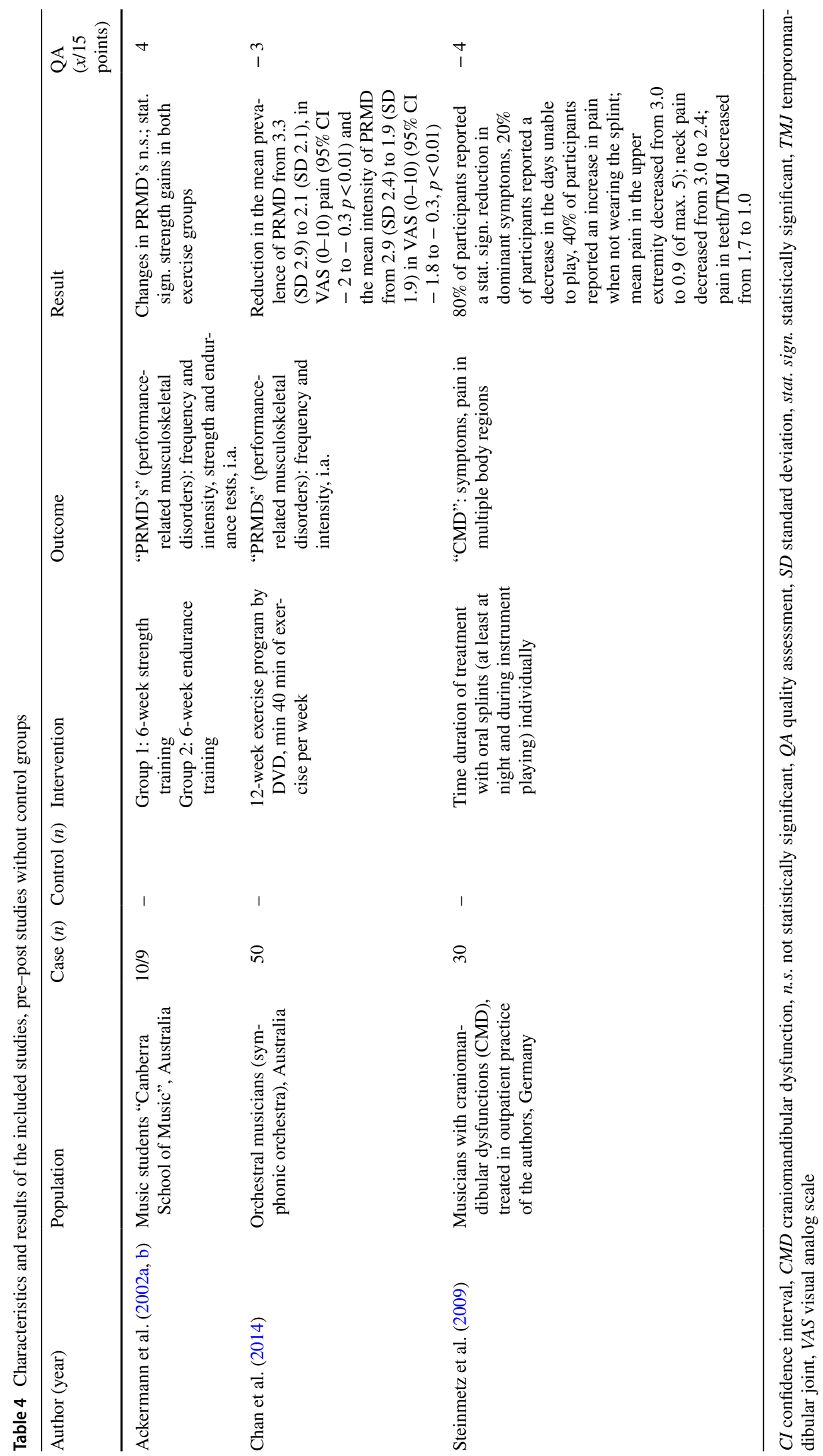




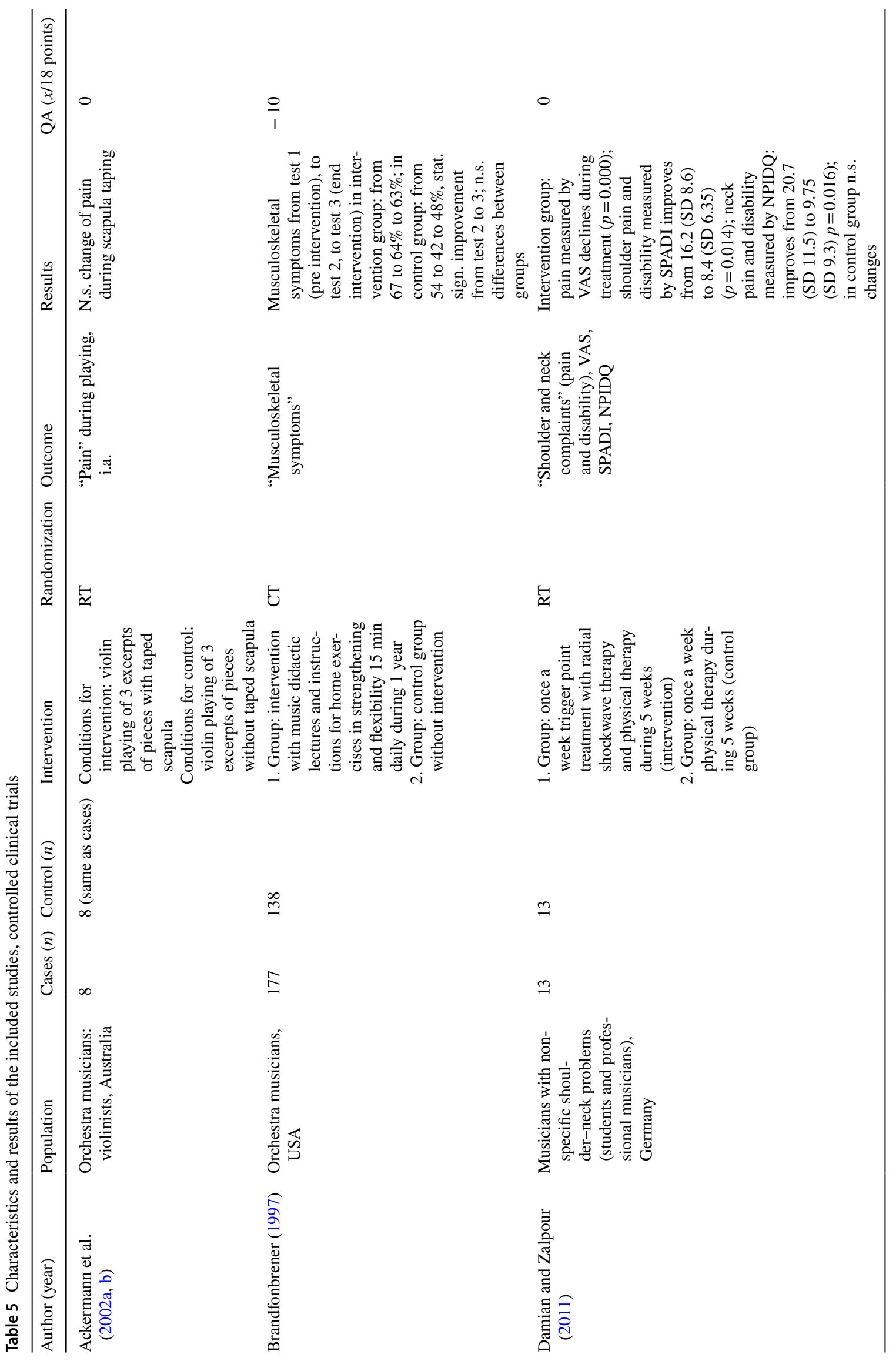




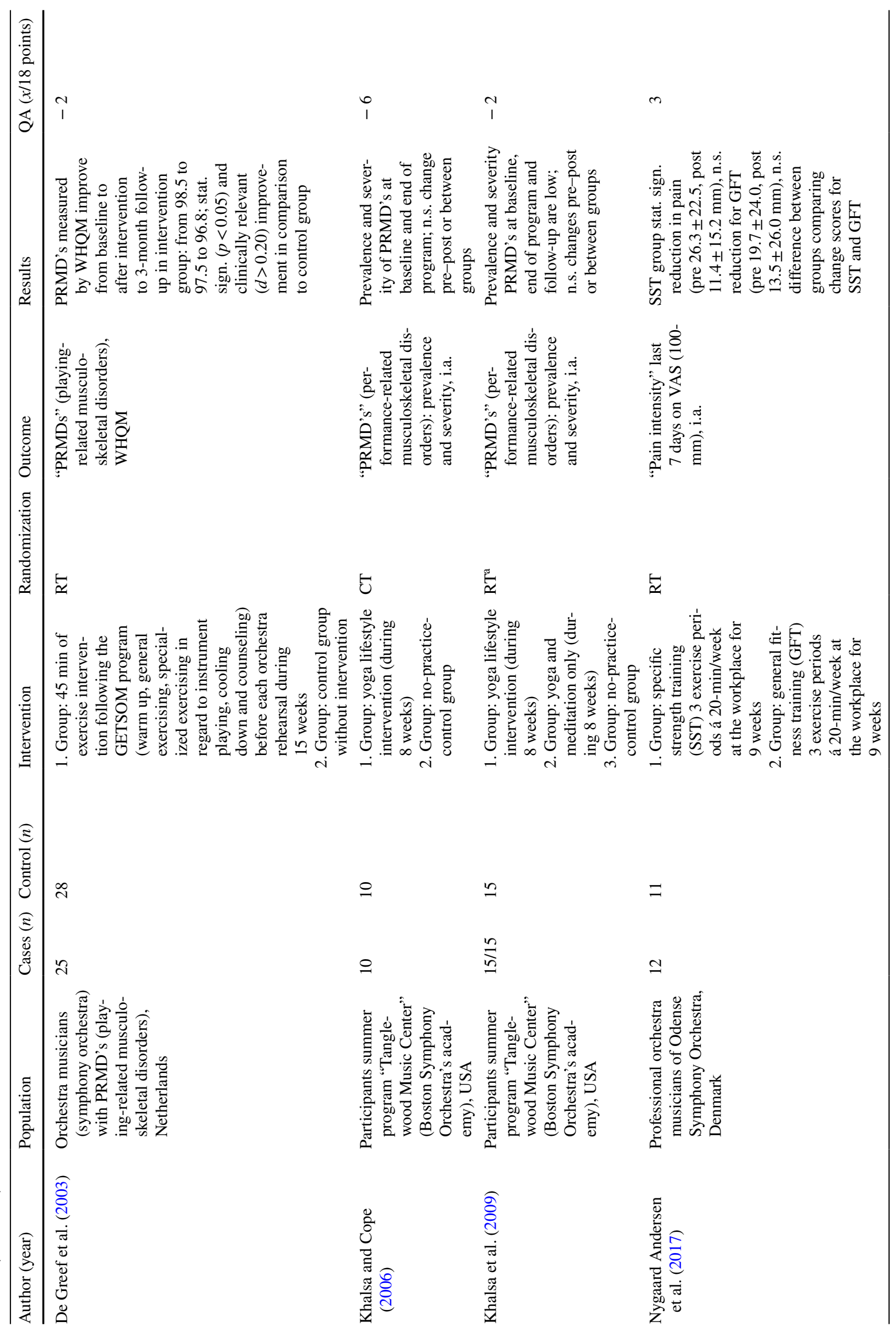




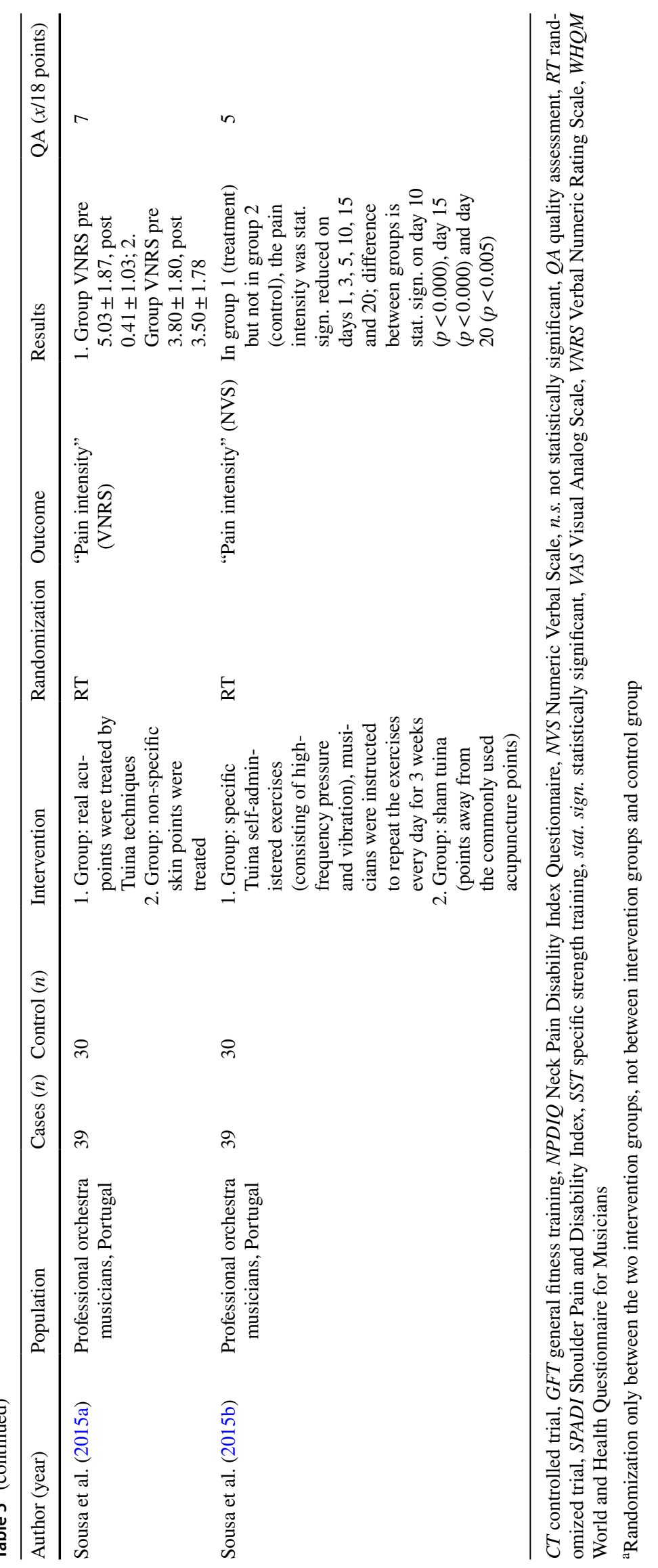


the same study population, reporting immediate effects and effects occurring after 3 weeks (Sousa et al. 2015a, b).

\section{Duration of study interventions}

The duration of the mostly physiotherapeutic interventions ranged from a single application given on 1 day with directly measured effects to interventions lasting 3, 5, 6, 8, 9, 12 and 15 weeks or interventions lasting up to 1 year. In one study, the treatment duration was individualized to each participant; the median treatment duration was 27 months, with a standard deviation of 16.7 months (Steinmetz et al. 2009).

\section{Study population of interventional studies}

Five studies explicitly included participants with complaints to investigate the effectiveness of the interventions (Sousa et al. 2015a, b; Damian and Zalpour 2011; de Greef et al. 2003; Steinmetz et al. 2009). Six studies included both musicians with complaints and musicians without complaints and investigated the prevalence and intensity of complaints before and after the interventions (Nygaard Andersen et al. 2017; Ackermann et al. 2002b; Brandfonbrener 1997; Chan et al. 2014; Khalsa and Cope 2006; Khalsa et al. 2009) or during the interventions compared to control conditions (Ackermann et al. 2002b).

\section{Used outcome parameters of interventional studies}

The intervention studies did not reveal evidence that the interventions were effective. No statistically significant changes in MCD were found in violinists after scapula taping, in musicians participating in yoga lifestyle interventions, or in orchestra musicians attending music didactic lectures and receiving instructions for home exercises or trigger point treatment with radial shockwave therapy combined with physical therapy or specific strength training in comparison to a control group (Ackermann et al. 2002a; Khalsa and Cope 2006; Khalsa et al. 2009; Brandfonbrener 1997; Damian and Zalpour 2011; Nygaard Andersen et al. 2017). However, two studies reported significant improvements within the treatment groups but not in the control group (Damian and Zalpour 2011; Nygaard Andersen et al. 2017). Tuina application and groningen exercise therapy did produce statistically significant reductions in pain in the treatment groups compared to the control groups (de Greef et al. 2003; Sousa et al. 2015a, b). Details are provided in Tables 4 and 5 .

\section{Quality assessment of interventional studies}

Pre-post studies without control groups The quality assessment scores of the three studies in this category were rated between -3 and 4 out of 15 possible points. Overall, there were significant methodological concerns. None of the studies reported sample size calculations, sufficient blinding or the use of objective, reliable and validated outcome measures. Inclusion and exclusion criteria were explicitly stated in only two studies (Ackermann et al. 2002b; Steinmetz et al. 2009). In one study, a group of participants received physiotherapy in addition to the examined intervention, but a subgroup analysis was not performed (Steinmetz et al. 2009).

Controlled clinical trials The quality assessment scores of the nine studies in this category ranged between -10 and 7 out of 18 possible points. Overall, noticeable methodological concerns included not reporting on how blinding was conducted, not using reliable randomization procedures and not providing sample size calculations. Only one study (Ackermann and Adams 2003) reported an analysis or avoidance of additional treatments. Only a few studies reported an intention-to-treat-analysis or reported using all the participants in their assigned groups for the analyses (Sousa et al. 2015a, b; de Greef et al. 2003; Nygaard Andersen et al. 2017). In four studies, the outcome measurements were not considered to be objective, reliable and validated (Brandfonbrener 1997; de Greef et al. 2003; Khalsa et al. 2009; Khalsa and Cope 2006).

\section{Case studies}

There were 28 case studies included, most of which were retrospective single case reports (Table 6). Almost all case studies described improvements in the complaints following the respective treatments or associations between risk factors and special complaints. We were unable to identify subsequent intervention studies to verify the treatment effects. The reported effects included surgical decompression procedures in nerve compression syndromes (Hoppmann 1997; Laha et al. 1978; Miliam and Basse 2009), surgical treatment in neurogenic thoracic outlet syndrome (Demaree et al. 2017), the use of individual orthotic or assistive devices (Anderson 1990; Dommerholt 2010; Price and Watson 2011; Sakai 1992; Wilson 1989), conservative combined treatments (Lederman 1996; Patrone et al. 1989) partly involving posture optimization (Manal et al. 2008; McFarland and Curl 1998; Potter and Jones 1993, 1995; Quarrier and Norris 2001) and physiotherapy with a special emphasis on mobilization of the radial and posterior interosseous nerves (Jepsen 2014), tensegrity massage and advice for positioning or leisure activities (Wilk et al. 2016). One report each exists for acupuncture (Molsberger and Molsberger 2012), EMG biofeedback (Levee et al. 1976), myofascial trigger point therapy (Dommerholt 2010) and the Feldenkrais method (Nelson 1989). 


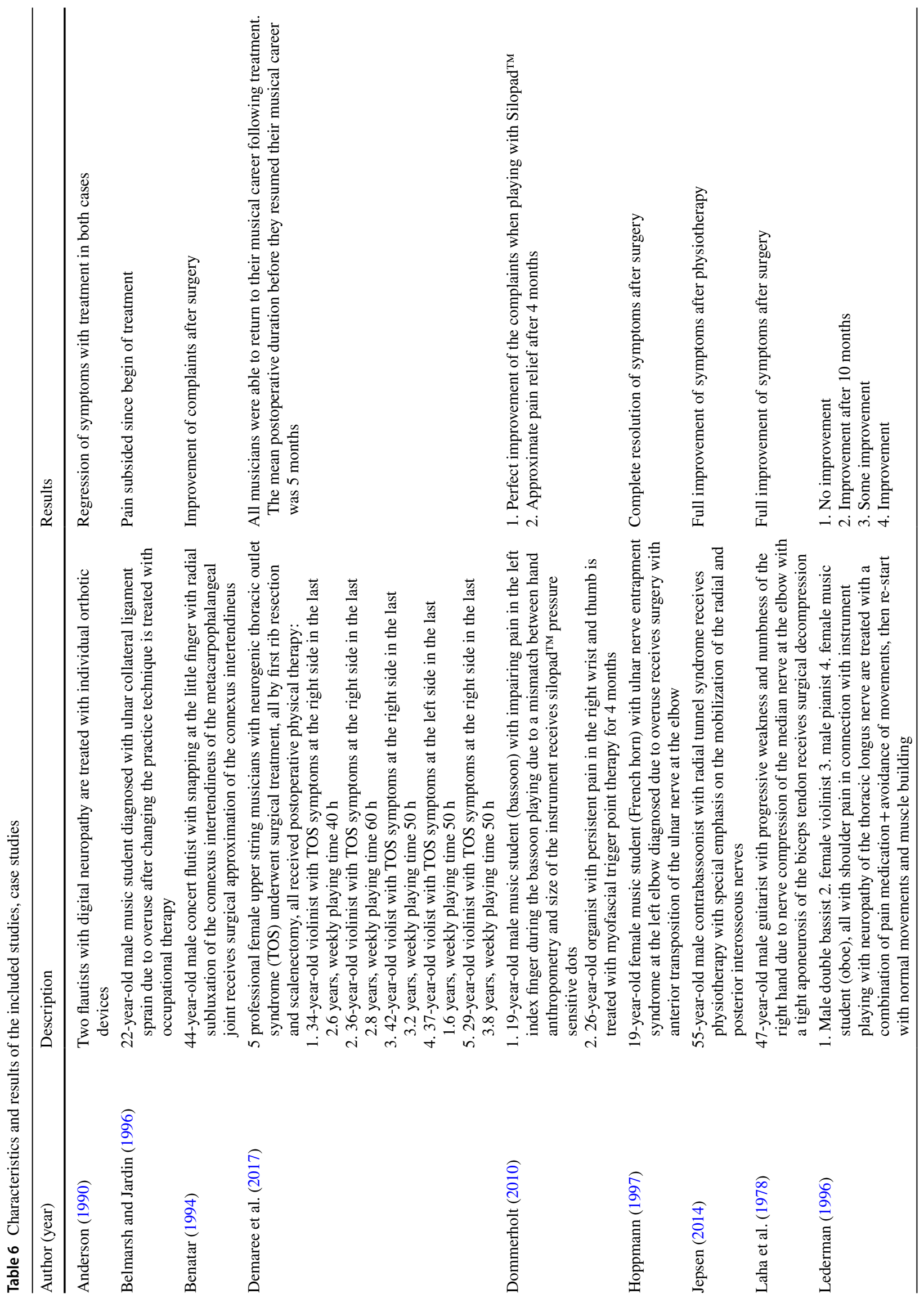




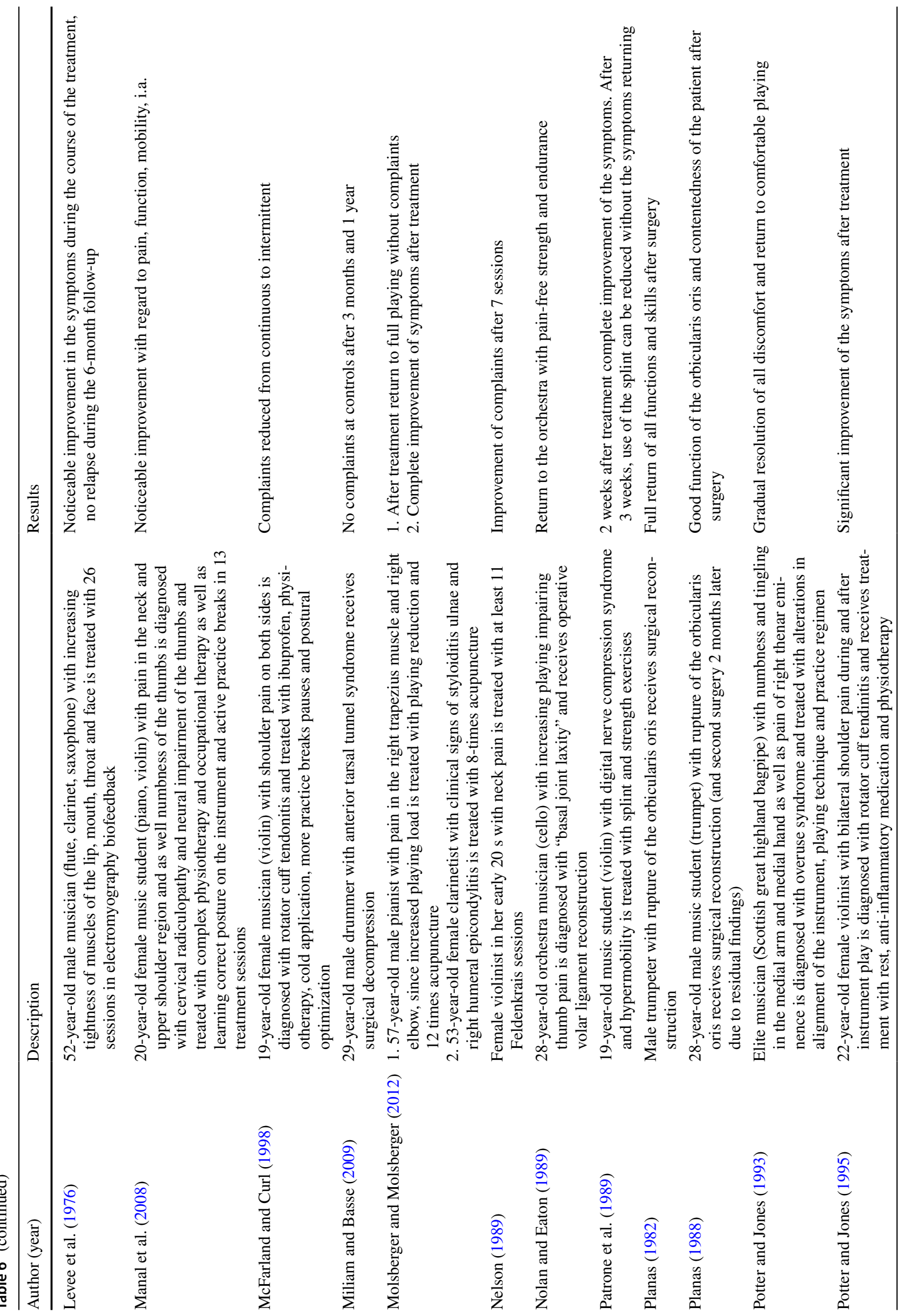




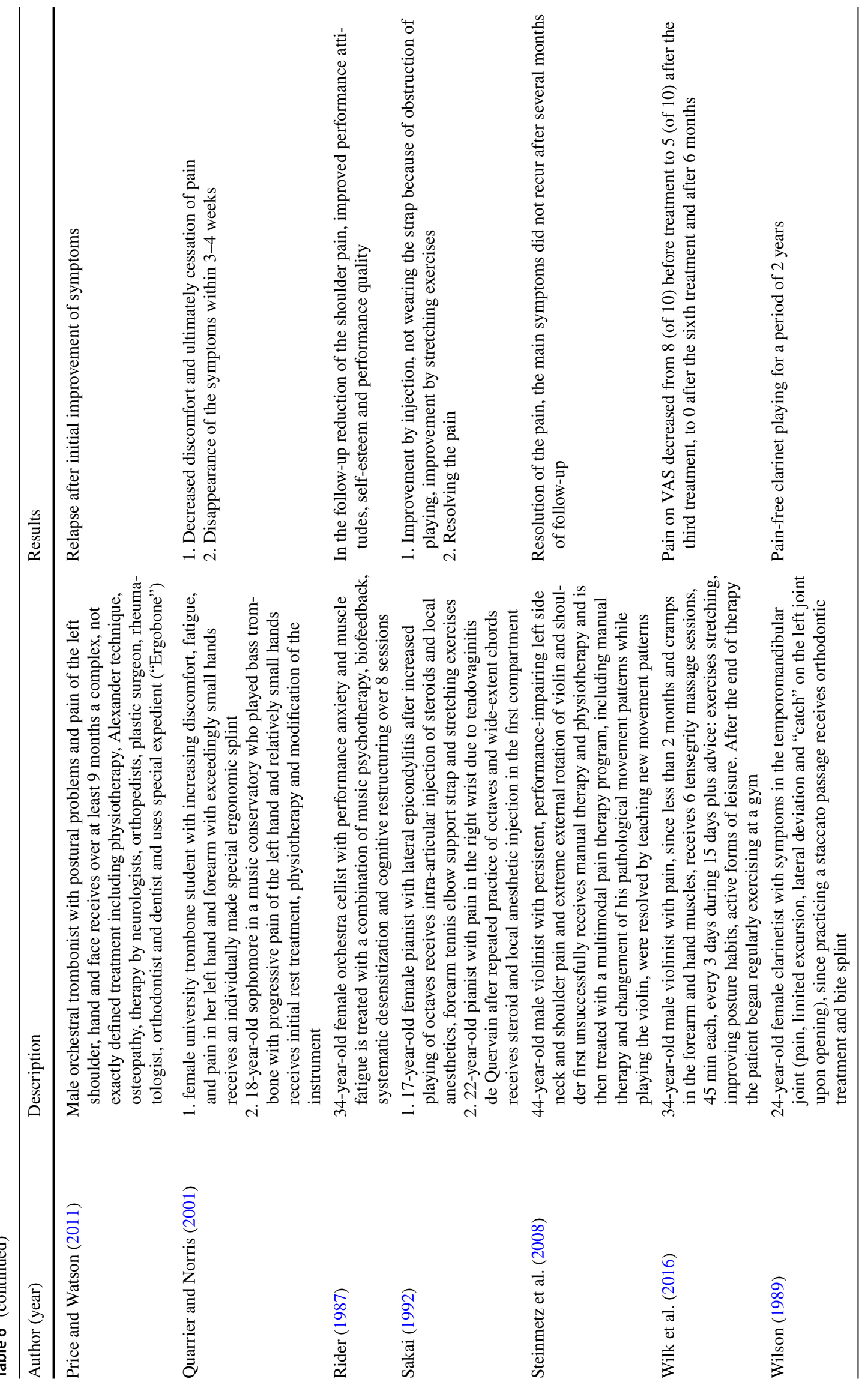




\section{Excluded studies}

At the full-text level, 195 studies did not fulfill the inclusion criteria and were not included. Examples of the excluded studies are provided as follows. The study population included participants under 16 years of age (Vinci et al. 2015; Rodríguez-Romero et al. 2016; Stanek et al. 2017; Ioannou and Altenmüller 2015; Yasuda et al. 2016; Hagberg et al. 2005; Rodriguez-Lozano 2008; Goodman and Staz 1989; Larsson et al. 1993; Mehrparvar et al. 2012), did not state the age range of participants (Zaza and Farewell 1997; Lopez and Martinez 2013; Manchester and Park 1996; Kreutz et al. 2008; Revak 1989; Brandfonbrener 2000; Lee et al. 2012; Tubiana and Chamagne 1993; Williamon and Thompson 2006; Zetterberg et al. 1998) or provided insufficient information on the outcomes of interest when separated into age subgroups (Furuya et al. 2006; Dawson 2001). Further reasons for exclusion included that the professional status was not clearly specified (Pedrazzini et al. 2015; Takata et al. 2016; Mehrparvar et al. 2012; Brandfonbrener 2000, 2002; Tubiana and Chamagne 1993; Lederman 2003), MCDs were not reported discriminatingly (Hiner et al. 1987; Spahn et al. 2001) or complaints were not clearly separated into non-musculoskeletal regions in the reported results (Kaneko et al. 2005).

\section{Discussion}

The study designs, terminology, and outcomes of the 109 studies included in this review were heterogeneous. The inclusion criteria were rarely mentioned throughout all study types, the analyses mostly did not check for major confounders, and the definition of exposure was often insufficient. In addition, the quality assessment of most studies included raised considerable methodological concerns. Therefore, sufficient statements cannot be provided for the prevalence, risk factors, prevention and effectiveness of treatment of MCD in professional musicians. Furthermore, a more profound differentiation, for example with regard to gender or the instrument played, is even less feasible.

In musicians' medicine, we regularly observe that professional musicians suffer from MCD due to high physical and psychological work-related demands. The wide range in the prevalence of MCD, reported in the included studies may reflect the heterogeneous and often unclear definitions used to assess complaints in musicians. We assume that causality was already inferred due to the use of terms such as "PRMD" or by asking the study participants about complaints that were caused by or noticed while playing music. Thus, the basic assumption of causality was not questioned. In musicians' medicine, we often lack validated assessment tools for MCD in relation to making music. However, some tools do exist, such as the Disabilities of The Arm, Shoulder and Hand (DASH) questionnaire (SooHoo et al. 2002; Hudak et al. 1996) with its optional sports/performing arts module.

From an epidemiological viewpoint, most of the included studies had only a small number of participants. Only one cross-sectional study (Fishbein et al. 1988; Middlestadt 1990; Middlestadt and Fishbein 1988) included a high number of participants $(n=2212)$. who were recruited from various US orchestras. Only this study was considered representative. However, even this study had considerable methodological shortcomings (see above).

The included studies had mostly a high risk of bias and little control of confounders. Some cross-sectional studies have been conducted on musicians in a single orchestra during a single rehearsal session. These studies likely suffered from a healthy-worker bias in addition to having little external validity or representativeness in the study results. When biographic data are gathered in cross-sectional studies, recall bias likely exists. Very few of the studies systematically assessed confounders that may have influenced MCD independently of the treatment, such as other physical loads, increased physical activity, working in the house and garden, unilateral strain by special sport discipline, carrying toddlers or providing home care to relatives. Individual preventive activities, such as sports, physical training, and relaxation, were not included as possible confounders. Additionally, correlations between instrument-specific workload (e.g., daily playing time) and complaints were not assessed. To assess the risk factors for MCD in musicians', observational cohort studies are needed that utilize a sufficient sample size, different instrument groups, workloads, or workplaces and account for physical activity and other risk factors. Clinical trials investigating conventional and complementary medicine approaches that differentiate between instrument groups are needed to assess effective therapy options for musicians.

Comparing our results to the literature we found seven systematic reviews about MCD in adult professional musicians (Zaza 1998; Bragge et al. 2006; Wu 2007; Baadjou et al. 2016; Jacukowicz 2016; Kok et al. 2016; Vervainioti and Alexopoulos 2015). The presented review is the first attempt to investigate the frequencies, risk factors and treatment options for MCD in musicians. Zaza (1998) reported that the prevalence of PRMD in adult classical musicians was comparable to that of work-related MCDs reported for other occupations. Due to the previously mentioned lack of evidence for the prevalence of PRMD, we are unable to draw a comparable conclusion. This finding is in line with another systematic review (Bragge et al. 2006) that concluded that the evidence did not provide sufficient information regarding the prevalence and risk factors associated with PRMDs in pianists due to common methodological limitations, including sampling/measurement biases, inadequate reporting of 
reliability/validity of the outcome measures, a lack of operational definitions for PRMD and a lack of statistical significance testing. In her work on the occupational risk factors of MCD in musicians, $\mathrm{Wu}$ (2007) reported that the etiology of MCD is multifactorial in instrumental musicians; however, she also pointed out that cross-sectional studies cannot investigate causality. This differs from our conclusion, since we could not identify studies that searched for risk factors using an appropriate study design. More recent systematic reviews also found methodological concerns (Baadjou et al. 2016; Jacukowicz 2016; Kok et al. 2016; Vervainioti and Alexopoulos 2015). In contrast to our review, the authors reported results from the subjects of each study. Baadjou et al. reported that previous musculoskeletal injuries, music performance anxiety, high levels of stress and being a female who plays a stringed instrument seem to be associated with more MCD (Baadjou et al. 2016). Kok et al. found a point prevalence of MCD in professional musicians ranging between 9 and 68\%, a 12-month prevalence between 41 and 93\% and a lifetime prevalence between 62 and $93 \%$. Ten out of 12 studies show a higher prevalence of MCD among women (Kok et al. 2016). However, the authors used a different scoring system to assess the quality of the included studies. In contrast to our assessment, the authors found that 13 out of 17 studies received high-quality scores (Kok et al. 2016). On the other hand, the results of the present study agree with the authors who reported that the current definition of PRMD does not provide causality of the complaints. We further emphasize the importance of using adequate and validated instruments for measuring outcomes in future studies. Jacukowicz reported on the psychosocial aspects of work, such as long hours at work, work content, high job demands, low control/influence, and a lack of social support were related to MCD (Jacukowicz 2016). Another systematic review included professional musicians as well as active members of a classical orchestra who were of at least 16 years of age. The review proposed that further research should include seven categories of stressors that affect classical instrumental musicians: public exposure, personal hazards, repertoire, competition, job context, injury/illness, and criticism (Vervainioti and Alexopoulos 2015).

\section{Limitations and strengths}

The presented systematic review is a comprehensive attempt to evaluate the quality of the available literature on the prevalence, risk factors, and effectiveness of prevention or treatment of MCD in professional musicians. Therefore, we included published observational studies (case-control studies, cohort studies and cross-sectional studies), interventional studies (controlled clinical trials and pre-post intervention studies without control group), case reports and case series reporting clinical interventions. Because the data were very heterogeneous, an assessment of publication bias, such as a funnel plot, was not feasible. The quality assessments of the included studies were performed according to the study protocol, and if a methodological procedure was not described in the assessed article, it was recorded as not done. This was very often the case, with very few procedures being explicitly described as not having been performed. This may have led to poorer evaluations of those studies that provided less detailed reporting or publications that were older than the current reporting guidelines. The real study method might have been underestimated based on the shortcomings of reporting. The authors were not contacted about the included studies, because several of the studies were performed more than 10 years ago. Regarding quality assessment and assessment of the bias risk of the original studies, a certain allowance for interpretation and discussion is generally required. Therefore, quality evaluations were each carried out by two people, and a consensus was drawn for each study after a detailed discussion. A limitation of the present review is that to allow for a quantitative estimation, the quality assessment instruments, which were modified by the authors, and the subsequent quantitative estimation were not validated previously. The term MCD comprises a large number of very different disorders. The aim of this review was to provide an overview of this research area as well as to search for clues about the causality between music making and diseases or disorders. Any restrictions to specified clinical diagnoses would, therefore, have been purely arbitrary and, given the conceptual uncertainty of numerous primary studies with many-sided overlaps, would have represented a random and, therefore, meaningless section of a complex, interwoven area.

\section{Conclusions}

The body of evidence regarding musculoskeletal disorders and complaints in professional musicians has grown substantially, since the publication of earlier reviews. However, studies analyzing prevalence, risk factors and effectiveness of the prevention or treatment of MCD amongst professional musicians, using today's methodological requirements, are still missing. To evaluate the extent of associations of practice and performance burden with $\mathrm{MCD}$, prospective, long-term cohort studies that properly take into account the influencing factors are still needed. To evaluate the effectiveness of specific treatment options for specific instrumental groups, prospective randomized confirmatory intervention studies are necessary. The use of well-defined diagnostic criteria for MCD in musicians is needed to avoid bias when selecting study participants. Strict and consistent diagnostic criteria would help to avoid the large variation in results. 
Establishing and implementing a validated and reliable set of outcome measurements is necessary. If it is possible to optimize the methodology as proposed above, relevant risk factors for MCD in musicians may be identified more precisely and allow for targeted prevention and intervention.

Acknowledgements We give our thanks to the native English-speaking editors at American Journal Experts for editing for proper English language, grammar, punctuation, spelling, and overall style (Certificate Verification Key: A58E-50C9-D188-34A7-40F4).

Author contributions Design of the study protocol: AB, KN, IF, SW. Performed the data search and study selection: KN, GR, AB, AS. Extracted and analyzed the data: KN, GR, AS, AB. Interpreted the data: AB, KN, GR, and AS. First draft of the manuscript: GR, KN. Revision of the paper and approval of the final version: GR, KN, IF, $\mathrm{AS}, \mathrm{AB}, \mathrm{SW}$.

\section{Compliance with ethical standards}

Conflict of interest The authors declare that they have no competing interests.

Open Access This article is distributed under the terms of the Creative Commons Attribution 4.0 International License (http://creativeco mmons.org/licenses/by/4.0/), which permits unrestricted use, distribution, and reproduction in any medium, provided you give appropriate credit to the original author(s) and the source, provide a link to the Creative Commons license, and indicate if changes were made.

\section{Appendix 1: Search algorithms}

\section{MEDLINE and EMBASE via OvidSP}

(musician \$1 OR instrumentalist\$1 OR orchestra OR symphony OR music student $\$ 1$ OR pianist $\$ 1$ OR harpsichordist $\$ 1$ OR organist $\$ 1$ OR string player $\$ 1$ OR violinist $\$ 1$ OR brass player $\$ 1$ OR cellist $\$ 1$ OR bassist $\$ 1$ OR violist $\$ 1$ OR harpist $\$ 1$ OR woodwind $\$ 1$ OR flute player $\$ 1$ OR recorder player $\$ 1$ OR oboist $\$ 1$ OR clarinetist $\$ 1$ OR bassoonist $\$ 1$ OR hornist\$1 OR saxophonist\$1 OR brass player\$1 OR trumpet player $\$ 1$ OR bugler\$1 OR trombone player\$1 OR tuba player\$1 OR euphonium player\$ OR percussionist $\$ 1$ OR drummer $\$ 1$ )

AND

(exp musculoskeletal diseases/ OR musculoskeletal disease/ OR exp pain/ OR exp cumulative trauma disorders/ OR cumulative trauma disorder/ OR exp "Sprains and Strains"/ OR musculoskeletal OR orthopedic OR pain OR cumulative trauma disorder $\$ 1$ OR overuse OR repetive strain injur\$ OR PRMD)

\section{AND}

(Cross-sectional study/ OR cross-sectional studies/ OR cohort studies/ OR cohort analysis/ OR case control studies/ OR case control study/ OR observational study/ OR case reports/ OR case report/ OR intervention studies/ OR intervention study/ OR exp clinical trial/ OR randomized controlled trial/ OR systematic review/ OR risk factor/ OR risk factors/ OR therapy/ OR therapeutics/ OR exp clinical trials as topic/ OR exp "clinical trial (topic) "/ OR double-blind method/ OR double-blind procedure/ OR prevalence/ OR incidence/ OR cross-sectional stud\$ OR cohort stud\$ OR case-control-stud\$ OR observational stud\$ OR case report\$1 OR intervention stud\$ OR clinical trial\$1 OR double-blind method OR randomized controlled trial $\$ 1$ OR prevalence OR incidence OR systematic review $\$ 1$ OR risk factor $\$ 1$ OR treat\$ OR therap\$)

\section{CINAHL via EbscoHost}

(musician* OR instrumentalist* OR orchestra OR symphony OR music student* OR pianist* OR harpsichordist* OR organist* OR string player* OR violinist* OR brass player* OR cellist* OR bassist* OR violist OR harpist* OR woodwind* OR flute player* OR recorder player OR oboist* OR clarinetist* OR bassoonist* OR hornist* OR saxophonist* OR brass player* OR trumpet player* OR bugler OR trombone player* OR tuba player* OR euphonium player* OR percussionist* OR drummer*)

AND

((MH "Pain+") OR (MH “Musculoskeletal Diseases+") OR (MH "Cumulative Trauma Disorders+") OR musculoskeletal OR orthopedic OR pain OR cumulative trauma disorder* OR overuse OR repetive strain injur* OR PRMD) AND

((MH “Cross Sectional Studies") OR (MH "Prospective Studies+") OR (MH "Case Control Studies+") OR (MH "Nonexperimental Studies+") OR (MH "Case Studies") OR (MH "Experimental Studies+") OR (MH "Systematic Review") OR (MH "Risk Factors") OR (MH "Clinical Trials+") OR (MH "Double-Blind Studies") OR (MH "Prevalence") OR (MH "Incidence")OR Cross-sectional stud* OR cross-sectional stud* OR cohort stud* OR case-control stud* OR observational stud* OR case report* OR intervention stud* OR clinical trial* OR double-blind-method OR prevalence OR incidence OR randomized controlled trial* OR systematic review* OR risk factor* OR treatment* OR therap*)

\section{PsycInfo + PsycArticles via EbscoHost}

(musician* OR instrumentalist* OR orchestra OR symphony OR music student* OR pianist* OR harpsichordist* OR organist* OR string player* OR violinist* OR brass player* OR cellist* OR bassist* OR violist OR harpist* OR woodwind* OR flute player* OR recorder player OR oboist* OR clarinetist* OR bassoonist* OR hornist* OR saxophonist* OR brass player* OR trumpet player* OR bugler OR 
trombone player* OR tuba player* OR euphonium player* OR percussionist* OR drummer*)

AND

((DE "Musculoskeletal Disorders" OR DE "Bone Disorders" OR DE "Joint Disorders" OR DE "Muscular Disorders") OR (DE "Pain" OR DE "Aphagia" OR DE "Back Pain" OR DE "Chronic Pain" OR DE "Headache" OR DE "Myofascial Pain" OR DE "Neuralgia" OR DE "Neuropathic Pain" OR DE "Somatoform Pain Disorder") OR musculoskeletal OR orthopedic OR pain OR cumulative trauma disorder* OR overuse OR repetive strain injur* OR PRMD)

AND

((DE "Cohort Analysis") OR (DE "Case Report") OR (DE "Clinical Trials") OR (DE "Risk Factors") OR (DE "Alternative Medicine" OR DE "Medical Treatment (General)" OR DE "Physical Treatment Methods" OR DE "Relaxation Therapy") OR (DE "Treatment") OR (DE "Clinical Trials")OR Cross-sectional stud* OR cross-sectional stud* OR cohort stud* OR case-control stud* OR observational stud* OR case report* OR intervention stud* OR clinical trial* OR double-blind method OR prevalence OR incidence OR randomized controlled trial* OR systematic review* OR risk factor* OR treatment* OR therap*)

\section{ERIC via EbscoHost}

(musician* OR instrumentalist* OR orchestra OR symphony OR music student* OR pianist* OR harpsichordist* OR organist* OR string player* OR violinist* OR brass player* OR cellist* OR bassist* OR violist OR harpist* OR woodwind* OR flute player* OR recorder player OR oboist* OR clarinetist* OR bassoonist* OR hornist* OR saxophonist* OR brass player* OR trumpet player* OR bugler OR trombone player* OR tuba player* OR euphonium player* OR percussionist* OR drummer*)

\section{AND}

(musculoskeletal OR orthopedic OR pain OR cumulative trauma disorder* OR overuse OR repetive strain injur* OR PRMD)

AND

((DE "Incidence") OR Cross-sectional stud* OR crosssectional stud* OR cohort stud* OR case-control stud* OR observational stud* OR case report* OR intervention stud* OR clinical trial* OR double-blind method OR prevalence OR incidence OR randomized controlled trial* OR systematic review* OR risk factor* OR treatment* OR therap*)

\section{Appendix 2: Quality assessment tools}

See online supplement.

\section{References}

Abréu-Ramos AM, Micheo WF (2007) Lifetime prevalence of upperbody musculoskeletal problems in a professional-level symphony orchestra: age, gender, and instrument-specific results. Med Probl Perform Artist 22(3):97-104

Ackermann B, Adams R (2003) Physical characteristics and pain patterns of skilled violinists. Med Probl Perform Artist 18(2):65-71

Ackermann B, Adams R, Marshall E (2002a) The effect of scapula taping on electromyographic activity and musical performance in professional violinists. Aust J Physiother 48(3):197-203

Ackermann B, Adams R, Marshall E (2002b) Strengh or endurance training for undergraduate music majors at university? Med Probl Perform Artists 17:33-41

Ackermann BJ, Kenny DT, Fortune J (2011) Incidence of injury and attitudes to injury management in skilled flute players. Work $\mathrm{J}$ Prev Assess Rehabil 40(3):255-259

Ackermann B, Driscoll T, Kenny DT (2012) Musculoskeletal pain and injury in professional orchestral musicians in Australia. Med Probl Perform Artist 27(4):181-187

Amorim MIT, Jorge AIL (2016) Association between temporomandibular disorders and music performance anxiety in violinists. Occup Med 66:558-563. https://doi.org/10.1093/occmed/kqw08 0

Anderson JI (1990) Orthotic device for flutists' digital nerve compression. Med Probl Perform Artists 5(3):91-93

Arnason K, Arnason A, Briem K (2014) Playing-related musculoskeletal disorders among Icelandic music students. Differences between students playing classical vs rhythmic music. Med Probl Perform Artists 29(2):74-79

Baadjou VA, Roussel NA, Verbunt JA, Smeets RJ, de Bie RA (2016) Systematic review: risk factors for musculoskeletal disorders in musicians. Occupational Medicine 66:614-622

Barton R et al (2008) Occupational performance issues and predictors of dysfunction in college instrumentalists. Med Probl Perform Artist 23:72-78

Bejjani FJ, Kaye GM, Benham M (1996) Musculoskeletal and neuromuscular conditions of instrumental musicians. Arch Phys Med Rehabil 77(4):406-413

Belmarsh K, Jardin G (1996) Student paper. An overview of upper extremity cumulative trauma disorders in pianists. Work 7:121-127

Benatar N (1994) Radial subluxation of the connexus intertendineus at the MP joint of the little finger in musicians treated by connexus intertendineus proximalization. J Hand Surg Br 19:81-87

Berque P, Gray H, McFadyen A (2016) Playing-related musculoskeletal problems among professional orchestra musicians in Scotland. Med Probl Perform Artist 31:78-86. https://doi.org/10.21091/ mppa.2016.2015

Blackie H, Stone R, Tiernan A (1999) An investigation of injury prevention among university piano students. Med Probl Perform Artist 14(3):141-149

Bragge P, Bialocerkowski A, McMeeken J (2006) A systematic review of prevalence and risk factors associated with playing-related musculoskeletal disorders in pianists. Occup Med 56(1):28-38. https://doi.org/10.1093/occmed/kqi177

Brandfonbrener AG (1997) Orchestral injury prevention. Intervention study. Med Probl Perform Artists 12(1):9-14

Brandfonbrener A (2000) Joint laxity and arm pain in musicians. Med Probl Perform Artists 15(2):72-74

Brandfonbrener AG (2002) Joint laxity and arm pain in a large clinical sample of musicians. Med Probl Perform Artist 17(3):113-115

(CASP) CASP (2013) CASP checklists. http://www.casp-uk.net/casptools-checklists. Accessed 7 Dec 2017 
Chan C, Driscoll T, Ackermann B (2013) The usefulness of on-site physical therapy-led triage services for professional orchestral musicians-a national cohort study. BMC Musculoskelet Disord 14(98):98. https://doi.org/10.1186/1471-2474-14-98

Chan C, Driscoll T, Ackermann B (2014) Exercise DVD effect on musculoskeletal disorders in professional orchestral musicians. Occup Med (Lond) 64(1):23-30. https://doi.org/10.1093/occme $\mathrm{d} / \mathrm{kqt} 117$

Crnivec R (2004) Assessment of health risks in musicians of the Slovene Philharmonic Orchestra, Ljubljana, Slovenia. Med Probl Perform Artists 19(3):140-145

Cruder C, Falla D, Mangili F, Azzimonti L, Araujo LS, Williamon A, Barbero M (2017) Profiling the location and extent of musicians' pain using digital pain drawings. Pain Pract 18(1):53-66

Damian M, Zalpour C (2011) Trigger point treatment with radial shock waves in musicians with nonspecific shoulder-neck pain: data from a special physio outpatient clinic for musicians. Med Probl Perform Artist 26(4):211-217

Davies J, Mangion S (2002) Predictors of pain and other musculoskeletal symptoms among professional instrumental musicians: elucidating specific effects. Med Probl Perform Artist 17(4):155-168

Dawson WJ (2001) Upper extremity overuse in instrumentalists. Med Probl Perform Artist 16(2):66-71

de Greef M, van Wijck R, Reynders K, Toussaint J, Hesseling R (2003) Impact of the Groningen Exercise Therapy for Symphony Orchestra Musicians program on perceived physical competence and playing-related musculoskeletal disorders of professional musicians. Med Probl Perform Artist 18(4):156-160

De Smet L, Ghyselen H, Lysens R (1998) Incidence of overuse syndromes of the upper limb in young pianists and its correlation with hand size, hypermobility and playing habits. Ann Hand Upper Limb Surg 17(4):309-313

Demaree CJ, Wang K, Lin PH (2017) Thoracic outlet syndrome affecting high-performance musicians playing bowed string instruments. Vascular 25:329-332

Dommerholt J (2010) Performing arts medicine_-instrumentalist musicians: part III-case histories. J Bodyw Mov Ther 14(2):127138. https://doi.org/10.1016/j.jbmt.2009.02.005

Eller N, Skylv G, Ostri B, Dahlin E, Suadicani P, Gyntelberg F (1992) Health and lifestyle characteristics of professional singers and instrumentalists. Occup Med (Lond) 42(2):89-92

Engquist K, Orbaek P, Jakobsson K (2004) Musculoskeletal pain and impact on performance in orchestra musicians and actors. Med Probl Perform Artist 19:55-61

Fishbein M, Middlestadt SE, Ottani V, Straus S, Ellis A (1988) Medical problems among ICSOM musicians: overview of a national survey. Med Probl Perform Artist 3(1):1-9

Fjellman-Wiklund A, Sundelin G (1998) Muscoloskeletal discomfort of music teachers: an eight-year perspective and psychosocial work factors. Int J Occup environ Health 4(2):89-98

Fjellmann-Wiklund A, Brulin C, Sundelin G (2003) Physical and psychosocial work-related risk factors associated with neck-shoulder discomfort in male and female music teachers. Med Probl Perform Artist 18:33-41

Fotiadis DG, Fotiadou EG, Kokaridas DG, Mylonas AC (2013) Prevalence of musculoskeletal disorders in professional symphony orchestra musicians in Greece: a pilot study concerning age, gender, and instrument-specific results. Med Probl Perform Artist 28:91-95

Fry HJH (1986) Incidence of overuse syndrome in the symphony orchestra. Med Probl Perform Artist 1:51-55

Furuya S, Nakahara H, Aoki T, Kinoshita H (2006) Prevalence and causal factors of playing-related musculoskeletal disorders of the upper extremity and trunk among Japanese pianists and piano students. Med Probl Perform Artist 21(3):112-117
Gasenzer ER, Klumpp MJ, Pieper D, Neugebauer EA (2017) The prevalence of chronic pain in orchestra musicians. Ger Med Sci. https://doi.org/10.3205/000242

Gohl AP, Clayton SZ, Strickland K, Bufford YD, Halle JS, Greathouse DG (2006) Median and ulnar neuropathies in university pianists. Med Probl Perform Artist 21:17-24

Goodman G, Staz S (1989) Occupational therapy for musicians with upper extremity overuse syndrome: patient perceptions regarding effectiveness of treatment. Med Probl Perform Artists 4(1):9-14

Green S, Higgins J (2011) Chapter 2: preparing a Cochrane review. The Cochrane Collaboration. http://handbook-5-1.cochrane.org/. Accessed 7 Dec 2017

Hagberg M, Thiringer G, Brandstrom L (2005) Incidence of tinnitus, impaired hearing and musculoskeletal disorders among students enroled in academic music education-a retrospective cohort study. Int Arch Occ Env Hea 78(7):575-583. https://doi. org/10.1007/s00420-005-0621-y

Harman SE (1982) Occupational diseases of instrumental musicians, literature review. Md State Med J 31(6):39-42

Harman SE (1993) Odyssey: the history of performing arts medicine. Md Med J 42(3):251-253

Heredia L, Hinkamp D, Brodsky M, Llapur C (2014) Playing-related problems among musicians of the orquesta buena vista social club (r) and supporting bands. Med Probl Perform Artist 29(2):80-85

Hiner SL, Brandt KD, Katz BP, French RN, Beczkiewicz TJ (1987) Performance-related medical problems among premier violinists. Med Probl Perform Art 2(2):67-71

Hodapp V, Langendörfer F, Bongard S (2009) Arbeitsbedingungen, gesundheitliche Beschwerden und Aufführungsängste bei professionellen Orchestermusikern. Musikphysiologie und Musikermedizin 15(2):99-113

Hoppmann RA (1997) Ulnar nerve entrapment in a French horn player. Wien Klin Wochenschr 109(19):777-780

Hoppmann RA, Patrone NA (1989) A review of musculoskeletal problems in instrumental musicians. Semin Arthritis Rheum 19(2):117-126

Hudak PL, Amadio PC, Bombardier C (1996) Development of an upper extremity outcome measure: the DASH (disabilities of the arm, shoulder and hand) [corrected]. The Upper Extremity Collaborative Group (UECG). Am J Ind Med 29(6):602-608. https:// doi.org/10.1002/(sici)1097-0274(199606)29:6\%3c602:aid-ajim4 $\% 3 \mathrm{e} 3.0 . \mathrm{co} ; 2-1$

Ioannou CI, Altenmüller E (2015) Approaches to and treatment strategies for playing-related pain problems among Czech instrumental music students. Med Probl Perform Artist 30(3):135-142

Jacukowicz A (2016) Psychosocial work aspects, stress and musculoskeletal pain among musicians. A systematic review in search of correlates and predictors of playing-related pain. Work J Prev Assess Rehabil 54(3):657-668. https://doi.org/10.3233/wor162323

Jepsen JR (2014) Posterior interosseous neuropathy in the distal radial tunnel in a contrabassoon musician. Med Probl Perform Artist 29(1):23-26

Kaneko Y, Lianza S, Dawson WJ (2005) Pain as an incapacitating factor in symphony orchestra musicians in São Paulo, Brazil. Med Probl Perform Artist 20(4):168-174

Kaufman-Cohen Y, Ratzon NZ (2011) Correlation between risk factors and musculoskeletal disorders among classical musicians. Occup Med (Lond) 61(2):90-95. https://doi.org/10.1093/occme d/kqq196

Kenny D, Ackermann B (2015) Performance-related musculoskeletal pain, depression and music performance anxiety in professional orchestral musicians: a population study. Psychol Music 43(1):43-60. https://doi.org/10.1177/0305735613493953 
Kenny DT, Driscoll T, Ackermann BJ (2016) Is playing in the pit really the pits?: pain, strength, music performance anxiety, and workplace satisfaction in professional musicians in stage, pit, and combined stage/pit orchestras. Med Probl Perform Artist 31(1):1-7

Khalsa SBS, Cope S (2006) Effects of a yoga lifestyle intervention on performance-related characteristics of musicians: a preliminary study. Med Sci Monit 12(8):CR325-CR331

Khalsa SB, Shorter SM, Cope S, Wyshak G, Sklar E (2009) Yoga ameliorates performance anxiety and mood disturbance in young professional musicians. Appl Psychophysiol Biofeedback 34(4):279-289. https://doi.org/10.1007/s10484-009-9103-4

Kim JY, Kim MS, Min SN, Cho YJ, Choi J (2012) Prevalence of playing-related musculoskeletal disorders in traditional Korean string instrument players. Med Probl Perform Art 27(4):212-218

Kochem FB, Silva JG (2017) Prevalence and associated factors of playing-related musculoskeletal disorders in Brazilian violin players. Med Probl Perform Artist 32(1):27-32

Kok LM, Vlieland TPMV, Fiocco M, Nelissen RGHH (2013) A comparative study on the prevalence of musculoskeletal complaints among musicians and non-musicians. Bmc Musculoskelet 14(9):2. https://doi.org/10.1186/1471-2474-14-9

Kok LM, Nelissen RGHH, Huisstede BMA (2015) Prevalence and consequences of arm, neck, and/or shoulder complaints among music academy students: a comparative study. Med Probl Perform Artist 30(3):163-168

Kok LM, Huisstede BM, Voorn VM, Schoones JW, Nelissen RG (2016) The occurrence of musculoskeletal complaints among professional musicians: a systematic review. Int Arch Occ Env Hea 89(3):373-396

Kovero O, Könönen M (1995) Signs and symptoms of temporomandibular disorders and radiologically observed abnormalities in the condyles of the temporomandibular joints of professional violin and viola players. Acta Odontol Scand 53(2):81-84

Kreutz G, Ginsborg J, Williamon A (2008) Music students' health problems and health-promoting behaviours. Med Probl Perform Artist 23(1):3-11

Kuorinka I, Jonsson B, Kilbom A, Vinterberg H, Biering-Sorensen F, Andersson G, Jorgensen K (1987) Standardised Nordic Questionnaires for the analysis of musculoskeletal symptoms. Appl Ergon 18(3):233-237

Laha RK, Lunsford LD, Dujovny M (1978) Lacertus fibrosus compression of the median nerve. J Neurosurg 48(5):838-841

Larsson L-G, Baum J, Mudholkar GS, Kollia GD (1993) Nature and impact of muscoloskeletal problems in a population of musicians. Med Probl Perform Artist 8:73-76

Leaver R, Harris EC, Palmer KT (2011) Musculoskeletal pain in elite professional musicians from British symphony orchestras. Occup Med (Lond) 61(8):549-555. https://doi.org/10.1093/occmed/ kqr129

Lederman RJ (1996) Long thoracic neuropathy in instrumental musicians: an often- unrecognized cause of shoulder pain. Med Probl Perform Artist 11(4):116-119

Lederman RJ (2003) Neuromuscular and musculoskeletal problems in instrumental musicians. Muscle Nerve 27(5):549-561. https:// doi.org/10.1002/mus. 10380

Lee SH, Carey S, Dubey R, Matz R (2012) Intervention program in college instrumental musicians, with kinematics analysis of cello and flute playing: a combined program of yogic breathing and muscle strengthening-flexibility exercises. Med Probl Perform Art 27(2):85-94

Levee JR, Cohen MJ, Rickles WH (1976) Electromyographic biofeedback for relief of tension in the facial and throat muscles of a woodwind musician. Biofeedb Self Regul 1(1):113-120

Liberati A, Altman DG, Tetzlaff J, Mulrow C, Gotzsche PC, Ioannidis JP, Clarke M, Devereaux PJ, Kleijnen J, Moher D (2009)
The PRISMA statement for reporting systematic reviews and meta-analyses of studies that evaluate health care interventions: explanation and elaboration. PLoS Med 6(7):e1000100. https:// doi.org/10.1371/journal.pmed.1000100

Lima RC, Magalhães Pinheiro TM, Dias EC, de Andrade EQ (2015) Development and prevention of work related disorders in a sample of Brazilian violinists. Work J Prev Assess Rehabil 51(2):273-280. https://doi.org/10.3233/wor-141904

Logue EJ, Bluhm S, Johnson MC, Mazer R, Halle JS, Greathouse DG (2005) Median and ulnar neuropathies in university cellists. Med Probl Perform Artist 20(2):70-76

Lopez TM, Martinez JF (2013) Strategies to promote health and prevent musculoskeletal injuries in students from the high conservatory of music of Salamanca, Spain. Med Probl Perform Artists 28(2):100-106

Manal TJ, Hunter-Giordanoo AO, Fontenot M (2008) Performing Arts Special Interest Group Management of a music student with thoracic, shoulder, arm and hand pain. Orthop Phys Ther Pract 20(3):150-153

Manchester RA (1988) The incidence of hand problems in music students. Med Probl Perform Artist 3(1):15-18

Manchester R, Flieder D (1991) Further observations on the epidemiology of hand injuries in music students. Med Probl Perform Artist 6(1):11-14

Manchester RA, Lustik S (1989) The short-term outcome of hand problems in music students. Med Probl Perform Artist 4(2):95-96

Manchester RA, Park S (1996) A case-control study of performancerelated hand problems in music students. Med Probl Perform Artist 11(1):20-23

Marques DN, Rosset-Llobet J, Marques MFF, Gurgel IGD, Augusto LGS (2003) Flamenco guitar as a risk factor for overuse syndrome. Med Probl Perform Artist 18(1):11-14

McFarland EG, Curl LA (1998) Shoulder problems in musicians. Md Med J 47:19-22

Mehrparvar AH, Mostaghaci M, Gerami RF (2012) Musculoskeletal disorders among Iranian instrumentalists. Med Probl Perform Artist 27(4):193-196

Middlestadt SE (1990) Medical problems of symphony orchestra musicians-from counting people with problems to evaluating interventions. Revista Interamericana De Psicologia 24(2):159-172

Middlestadt SE, Fishbein M (1988) Health and occupational correlates of perceived occupational stress in symphony orchestra musicians. J Occup Med 30(9):687-692

Middlestadt SE, Fishbein M (1989) The prevalence of severe musculoskeletal problems among male and female symphonyorchestra string players. Med Probl Perform Artist 4(1):41-48

Milan KR (1996) Literature review of common injuries in the performing artist. Orthop Phys Ther Clin N Am 5(4):421-453

Miliam PB, Basse PN (2009) Anterior tarsal tunnel syndrome. [Danish] (Anterior tarsaltunnelsyndrom.). Ugeskrift for laeger 171(14):1194

Miller G, Peck F, Watson JS (2002) Pain disorders and variations in upper limb morphology in music students. Med Probl Perform Artist 17:169-172

Mishra W, De A, Gangopadhyay S, Chandra AM (2013) Playingrelated musculoskeletal disorders among indian tabla players. Med Probl Perform Artist 28(2):107-111

Moher D, Liberati A, Tetzlaff J, Altman DG, Group P (2009) Preferred reporting items for systematic reviews and meta-analyses: the PRISMA statement. PLoS Med 6(7):e1000097. https ://doi.org/10.1371/journal.pmed.1000097

Molsberger F (1991) Der Künstler als Patient. Wien Klin Wochenschrift 103(8):236-241

Molsberger F, Molsberger A (2012) Acupuncture in treatment of musculoskeletal disorders of orchestra musicians. Work 41(1):5-13. https://doi.org/10.3233/WOR-2012-1235 
Monaco E, Vicaro V, Catarinozzi E, Rossi M, Prestigiacomo C (2012) Patologie muscolo-scheletriche nei musicisti des "Teatro dell'Opera" di Roma. Giorno italiana di medicina del lavoro ed ergonomica 34(2):158-163

Moore M, DeHaan L, Ehrenberg T, Gross L, Magembe C (2008) Clinical assessment of shoulder impingement factors in violin and viola players. Med Probl Perform Artist 23:155-163

Moraes GFdS, Antunes AP (2012) Musculoskeletal disorders in professional violinists and violists. Systematic review. Acta Ortopedica Brasileira 20(1):43-47. https://doi.org/10.1590/ S1413-78522012000100009

Navia Alvarez P, Arraez Aybar A, Alvarez Martinez P, Ardiaca Burgues L (2007) Incidence and risk factors for neck pain in Spanish orchestras musicians. Mapfre Med 18:27-35

Nelson SH (1989) Playing with the entire self: the Feldenkrais method and musicians. Semin Neurol 9(2):97-104. https:// doi.org/10.1055/s-2008-1041310

(NHLBI) NHLaBI study quality assessment tools. https://www. nhlbi.nih.gov/health-topics/study-quality-assessment-tools. Accessed 7 Dec 2017

Nolan WB, Eaton RG (1989) Thumb problems of professional musicians. Med Probl Perform Artist 4:20-22

Nusseck M, Mornell A, Voltmer E, Kötter T, Schmid B, Blum J, Türk-Espitalier A, Spahn C (2017) Gesundheit und Präventionsverhalten von Musikstudierenden an verschiedenen deutschen Musikhochschulen. Fachzeitschrift Musikphysiologie und Musikermedizin 24(2):67-84

Nygaard Andersen L, Mann S, Juul-Kristensen B, SØgaard K (2017) Comparing the impact of specific strength training vs general fitness training on professional symphony orchestra musicians: a feasibility study. Med Probl Perform Artist 32(2):94-100. https://doi.org/10.21091/mppa.2017.2016

Nyman T, Wiktorin C, Mulder M, Johansson YL (2007) Work postures and neck-shoulder pain among orchestra musicians. Am J Ind Med 50(5):370-376. https://doi.org/10.1002/ajim.20454

Paarup HM, Baelum J, Holm JW, Manniche C, Wedderkopp N (2011) Prevalence and consequences of musculoskeletal symptoms in symphony orchestra musicians vary by gender: a cross-sectional study. BMC Musculoskelet Disord 12:223. https://doi.org/10.1186/1471-2474-1112-1223, https://doi. org/10.1186/1471-2474-12-223

Papandreou M, Vervainioti A (2010) Work-related musculoskeletal disorders among percussionists in Greece: a pilot study. Med Probl Perform Artist 25(3):116-119

Patrone NA, Hoppmann RA, Wahley J, Schmidt R (1989) Digital nerve compression in a violinist with benign hypermobility: a case study. Med Probl Perform Artist 4(2):91

Pedrazzini A, Martelli A, Tocco S (2015) Niccolo Paganini: the hands of a genius. Acta Bio Medica de 1 Ateneo Parmense 86(1):27-31

Piatkowska K, Wnuk B, Blicharska I, Rychlik M, Durmala J (2016) Cervical pain in young professional musicians-quality of life. Ortoped Traumatol Rehabil 18(1):21-29

Planas J (1982) Rupture of the orbicularis oris in trumpet players (Satchmo's syndrome). Plast Reconstr Surg 69:690-693

Planas J (1988) Further experience with rupture of the orbicularis oris in trumpet players. Plast Reconstr Surg 81:975-977

Potter P, Jones IC (1993) Musculoskeletal symptoms associated with the great Highland bagpipe. Med Probl Perform Artist 8(3):81

Potter PJ, Jones IC (1995) Medical problems affecting musicians. Can Fam Physician 41:2121-2128

Price K, Watson AHD (2011) Postural problems of the left shoulder in an orchestral trombonist. Work 40(3):317-324. https://doi. org/10.3233/WOR-2011-1238

Quarrier NF, Norris RN (2001) Adaptations for trombone performance: ergonomic interventions. Med Probl Perform Artist 16:77-80
Ramazzini B (1705) Of the diseases of musick masters, chaunters, and others of the like profession. In: Ramazzini B (ed) A treatise of the diseases of tradesmen. Andrew Bell, London, pp 221-225

Raymond DM 3rd, Romeo JH, Kumke KV (2012) A pilot study of occupational injury and illness experienced by classical musicians. Workplace Health Saf 60(1):19-24. https://doi.org/10.3928/21650 799-20111227-01

Rein S, Fabian T, Zwipp H, Heineck J, Weindel S (2010) The influence of profession on functional ankle stability in musicians. Med Probl Perform Artist 25:22-28

Revak JM (1989) Incidence of upper extremity discomfort among piano students. Am J Occup Ther 43(3):149-154

Rickert D, Barrett M, Halaki M, Driscoll T, Ackermann B (2012) A study of right shoulder injury in collegiate and professional orchestral cellists: an investigation using questionnaires and physical assessment. Med Probl Perform Artist 27(2):65-73

Rider MS (1987) Music therapy: therapy for debilitated musicians. Music Ther Perspect 4:40-43

Rodriguez-Lozano FJEA (2008) Bruxism related to violin playing. Med Probl Perform Artist 23(1):12-15

Rodríguez-Romero B, Pérez-Valiño C, Ageitos-Alonso B, Pértega-Díaz S (2016) Prevalence and associated factors for musculoskeletal pain and disability among Spanish music conservatory students. Med Probl Perform Artist 31(4):193-200. https://doi.org/10.21091 /mppa.2016.4035

Sakai N (1992) Hand pain related to keyboard techniques in pianists. Med Probl Perform Artist 7(2):63-65

Sakai N (2002) Hand pain attributed to overuse among professional pianists - a study of 200 cases. Med Probl Perform Artist 17(4):178-180

Sakai N, Shimawaki S (2010) Measurement of a number of indices of hand and movement angles in pianists with overuse disorders. J Hand Surg Eur 35(6):494-498. https://doi.org/10.1177/17531 93409352405

Schäcke G, Kwiatkowski A, Wellstein F (1986) Muskel-Skelett-Beschwerden bei Orchestermusikern. Fortschr Med 104(6):126-128

Shields N, Dockrell S (2000) The prevalence of injuries among pianists in music schools in Ireland. Med Probl Perform Artist 15(4):155-160

Singer K, Lakond W (1932) Diseases of the musical profession: a systematic presentation of their causes, symptoms and methods of treatment. Greenberg, New York

SooHoo NF, McDonald AP, Seiler JG, McGillivary GR (2002) Evaluation of the construct validity of the DASH questionnaire by correlation to the SF-36. J Hand Surg Am 27(3):537-541

Sousa CM, Coimbra D, Machado J, Greten HJ (2015a) Effects of selfadministered exercises based on Tuina techniques on musculoskeletal disorders of professional orchestra musicians: a randomized controlled trial. J Integr Med 13(5):314-318

Sousa CM, Moreira L, Coimbra D, Machado J, Greten HJ (2015b) Immediate effects of Tuina techniques on working-related musculoskeletal disorder of professional orchestra musicians. J Integr Med 13(4):257-261

Sousa CM, Pereira Machado J, Johannes Greten H, Coimbra D (2016) Occupational diseases of professional orchestra musicians from Northern Portugal. Med Probl Perform Artist 31(1):8-12. https:// doi.org/10.21091/mppa.2016.1002

Spahn C, Hildebrandt H, Seidenglanz K (2001) Effectiveness of a prophylactic course to prevent playing-related health problems of music students. Med Probl Perform Artist 16(1):24-31

Spahn C, Richter B, Altenmüller E (2011) Musikermedizin—eine Einführung. Musikermedizin: Diagnostik, Therapie und Prävention von musikerspezifischen Erkrankungen. Schattauer GmbH, Stuttgart, pp 1-5

Stanek JL, Komes KD, Murdock FA Jr (2017) A cross-sectional study of pain among U.S. college music students and faculty. Med 
Probl Perform Artists 32(1):20-26. https://doi.org/10.21091/ mppa.2017.1005

Stanhope J, Milanese S, Grimmer K (2014) University woodwind students' experiences with playing-related injuries and their management: a pilot study. J Pain Res 7:133-148. https://doi. org/10.2147/JPR.S49620

Steinmetz A, Möller H (2007) Dysfunktionen des Bewegungssystems bei jungen Musikern. Musikphysiologie und Musikermedizin 14(1):12-16

Steinmetz A, Ridder PH, Reichelt A (2003) Craniomandibuläre Dysfunktionen als ein Einflussfaktor für die Entstehung von Überlastungsbeschwerden bei Geigern. Musikphysiologie und Musikermedizin 10:203-209

Steinmetz A, Ridder PH, Reichelt A (2006) Craniomandibular dysfunction and violin playing: Prevalence and theinfluence of oral splints on head and neck muscles in violinists. Med Probl Perform Artist 21(4):183-189

Steinmetz A, Seidel W, Niemier K (2008) Shoulder pain and holding position of the violin-a case report. Med Probl Perform Artist 23:79-81

Steinmetz A, Ridder PH, Methfessel G, Muche B (2009) Professional musicians with craniomandibular dysfunctions treated with oral splints. Cranio 27(4):221-230. https://doi.org/10.1179/ crn.2009.033

Steinmetz A, Moller H, Seidel W, Rigotti T (2012) Playing-related musculoskeletal disorders in music students-associated musculoskeletal signs. Eur J Phys Rehabil Med 48(4):625-633

Steinmetz A, Zeh A, Delank KS, Peroz I (2014) Symptoms of craniomandibular dysfunction in professional orchestra musicians. Occup Med (Lond) 64:17-22. https://doi.org/10.1093/occmed/ kqt148

Steinmetz A, Scheffer I, Esmer E, Delank KS, Peroz I (2015) Frequency, severity and predictors of playing-related musculoskeletal pain in professional orchestral musicians in Germany. Clin Rheumatol 34:965-973

Steinmetz A, Claus A, Hodges PW, Jull GA (2016) Neck muscle function in violinists/violists with and without neck pain. Clin Rheumatol 35:1045-1051

Takata K, Onuma K, Sukegawa K, Takaso M (2016) Osteochondritis dissecans of the fourth proximal interphalangeal joint in a Japanese drummer. Case Rep Plast Surg Hand Surg 3(1):83-85

Tubiana R, Chamagne P (1993) Occupational arm ailments in musicians. Bull Acad Natl Med 177(2):203-212 (discussion 206-212)

Vervainioti A, Alexopoulos EC (2015) Job-related stressors of classical instrumental musicians a systematic qualitative review. Med Probl Perform Artist 30(4):197-202

Vinci S, Smith A, Ranelli S (2015) Selected physical characteristics and playing-related musculoskeletal problems in adolescent string instrumentalists. Med Probl Perform Artist 30(3):143-151

Wahlström Edling C, Fjellman-Wiklund A (2009) Musculoskeletal Disorders and asymmetric playing postures of the upper extremity and back in music teachers: a pilot study. Med Probl Perform Artist 24:113-118

Wilk I, Kurpas D, Andrzejewski W, Okreglicka-Forysiak E, Gworys B, Kassolik K (2016) The application of tensegrity massage in a professionally active musician-case report. Rehabil Nurs $\mathbf{J}$ 41(3):179-192

Williamon A, Thompson S (2006) Awareness and incidence of health problems among conservatoire students. Psychol Music 34(4):411-430

Wilson JS (1989) A dental appliance for a clarinettist experiencing temporomandibular-joint pain. Med Probl Perform Artist 4(3):118-121

Woldendorp KH, Boonstra AM, Tijsma A, Arendzen JH, Reneman MF (2016) No association between posture and musculoskeletal complaints in a professional bassist sample. Eur J Pain 20(3):399-407. https://doi.org/10.1002/ejp.740

Woldendorp KH, Boonstra AM, Arendzen JH, Reneman MF (2017) Variation in occupational exposure associated with musculoskeletal complaints: a cross-sectional study among professional bassists. Int Arch Occup Environ Health 91:215-223

Wu SJ (2007) Occupational risk factors for musculoskeletal disorders in musicians: a systematic review. Med Probl Perform Artist 22(2):43-51

Yasuda E, Honda K, Hasegawa Y, Matsumura E, Fujiwara M, Hasegawa M, Kishimoto H (2016) Prevalence of temporomandibular disorders among junior high school students who play wind instruments. Int J Occup Med Environ Health 29(1):69-76

Yeung E, Chang W, Pan F, Sau P, Tsui M, Yu B, Zaza C (1999) A survey of playing-related musculoskeletal problems among professional orchestral musicians in Hong Kong. Med Probl Perform Artist 14:43-47

Yoshimura E, Paul PM, Aerts C, Chesky K (2006) Risk factors for piano-related pain among college students. Med Probl Perform Artist 21:118-125

Zaza C (1998) Playing-related musculoskeletal disorders in musicians: a systematic review of incidence and prevalence. CMAJ 158(8):1019-1025

Zaza C, Farewell VT (1997) Musicians' playing-related musculoskeletal disorders: an examination of risk factors. Am J Ind Med 32(3):292-300

Zetterberg C, Backlund H, Karkson J, Werner H, Olsson L (1998) Musculoskeletal problems among male and female music students. Med Probl Perform Artist 13(4):160-166

Zuskin E, Schachter EN, Kolcic I, Polasek O, Mustajbegovic J, Arumugam U (2005) Health problems in musicians-a review. Acta Dermatovenerol Croat 13(4):247-251

Publisher's Note Springer Nature remains neutral with regard to jurisdictional claims in published maps and institutional affiliations. 